\title{
The Native Rat Olfactory Cyclic Nucleotide-Gated Channel Is Composed of Three Distinct Subunits
}

\author{
Wolfgang Bönigk, ${ }^{1}$ Jonathan Bradley, ${ }^{2}$ Frank Müller, ${ }^{1}$ Federico Sesti, ${ }^{1}$ Ingrid Boekhoff, ${ }^{3}$ Gabriele V. Ronnett, ${ }^{4}$ \\ U. Benjamin Kaupp, ${ }^{1}$ and Stephan Frings ${ }^{1}$ \\ ${ }^{1}$ Forschungszentrum Jülich, Institut für Biologische Informationsverarbeitung, 52425 Jülich, Germany, ${ }^{2}$ Ecole Normale \\ Supérieure, Laboratoire de Neurobiologie, 75005 Paris, France, 3'Universität Hohenheim, Institut für Physiologie, 70574 \\ Stuttgart, Germany, and ${ }^{4}$ Department of Neurosciences and Neurology, Johns Hopkins University School of Medicine, \\ Baltimore, Maryland 21205
}

Cyclic nucleotide-gated (CNG) channels play central roles in visual and olfactory signal transduction. In the retina, rod photoreceptors express the subunits $\mathrm{CNC} \alpha 1$ and $\mathrm{CNC} \beta 1 \mathrm{a}$. In cone photoreceptors, only $\mathrm{CNC} \alpha 2$ expression has been demonstrated so far. Rat olfactory sensory neurons (OSNs) express two homologous subunits, here designated $\mathrm{CNC} \alpha 3$ and $\mathrm{CNC} \alpha 4$. This paper describes the characterization of $\mathrm{CNC} \beta 1 \mathrm{~b}$, a third subunit expressed in OSNs and establishes it as a component of the native channel. $\mathrm{CNC} \beta 1 \mathrm{~b}$ is an alternate splice form of the rod photoreceptor $\mathrm{CNC} \beta 1$ a subunit. Analysis of mRNA and protein expression together suggest co- expression of all three subunits in sensory cilia of OSNs. From single-channel analyses of native rat olfactory channels and of channels expressed heterologously from all possible combinations of the $\mathrm{CNC} \alpha 3,-\alpha 4$, and $-\beta 1$ b subunits, we conclude that the native CNG channel in OSNs is composed of all three subunits. Thus, CNG channels in both rod photoreceptors and olfactory sensory neurons result from coassembly of specific $\alpha$ subunits with various forms of an alternatively spliced $\beta$ subunit.

Key words: $c A M P$; cGMP; sensory transduction; olfaction; ion channels; channel structure; subunit
Sensory transduction in retinal photoreceptors and olfactory sensory neurons (OSNs) is mediated by ion channels that are gated open by the intracellular messengers cGMP and cAMP, respectively. Cyclic nucleotide-gated (CNG) channels can be composed of several distinct subunits in unknown stoichiometry (for review, see Kaupp, 1995; Finn et al., 1996; Zagotta and Siegelbaum, 1996). Rod and cone photoreceptors, as well as OSNs, each express a specific principal subunit, commonly referred to as $\alpha$ subunit, which is responsible for many of the key channel characteristics. When heterologously expressed, $\alpha$ subunits form functional channels, probably by assembling into homotetrameric complexes (Gordon et al., 1996; Liu et al., 1996). We have adopted the following nomenclature for the vertebrate $\mathrm{CNG}$ channel $\alpha$ subunits expressed in sensory tissue: $\mathrm{CNC} \alpha 1$ in $\operatorname{rod}$ photoreceptors (Kaupp et al., 1989), CNC $\alpha 2$ in cone photoreceptors (Bönigk et al., 1993; Weyand et al., 1994), and $\mathrm{CNC} \alpha 3$ in OSNs (Dhallan et al., 1990; Ludwig et al., 1990). These homologous $\alpha$ subunits share common structural features such as an

Received Feb. 10, 1999; accepted March 22, 1999.

This work was supported by grants from the European Community (CHRXCT94-0543) and the Ministerium für Wissenschaft und Forschung des Landes Nordrhein-Westfalen (IVA6-10201095) to U.B.K, by the Human Frontiers Science Program (LT-448-96) to J.B., by the Deutsche Forschungsgemeinschaft (Schwerpunktprogramm "Molekulare Sinnesphysiologie") to S.F., and by the Develbiss Fund, the McKnight Foundation, and National Institute on Deafness and Other Communication Disorders/National Institutes of Health Grant RO1DC02979 to G.V.R. We thank Dr. Philippe Ascher for valuable comments on this manuscript. We gratefully acknowledge the assistance of Kerstin Bach, Mechthilde Bruns, and Helga Vent. We thank Dr. Heinz Körschen for the anti-CNC $\beta 1$ a antibody FPc21K.

The CNC $\beta 1 \mathrm{~b}$ sequence has been deposited in GenBank (accession number AF068572).

Correspondence should be addressed to Professor U. B. Kaupp, Forschungszentrum Jülich, IBI-1, 52425 Jülich, Germany.

Dr. Sesti's present address: Yale University, School of Medicine, BCMM, 295 Congress Avenue, New Haven, CT 06536.

Copyright (C) 1999 Society for Neuroscience $\quad 0270-6474 / 99 / 195332-16 \$ 05.00 / 0$
S4-like voltage-sensor motif (Jan and Jan, 1990), a pore region (Goulding et al., 1992; Bönigk et al., 1993), a cyclic nucleotidebinding fold (Kaupp et al., 1989; Dhallan et al., 1990; Ludwig et al., 1990), and a similar transmembrane topology (Henn et al., 1995).

Additional subunits have been discovered for the rod (Chen et al., 1994; Körschen et al., 1995) and olfactory (Bradley et al., 1994; Liman and Buck, 1994; Sautter et al., 1998) CNG channels. These subunits have the same structural features as described for the $\alpha$ subunits, with some added diversity. The second subunit of rod photoreceptors, $\mathrm{CNC} \beta 1 \mathrm{a}$, does not form functional channels on its own, but when coexpressed with $\mathrm{CNC} \alpha 1$ it bestows the hetero-oligomeric channel with properties characteristic of the native rod channel: in particular, flickery gating, sensitivity to blockage by l-cis-diltiazem (Chen et al., 1993), and modulation by $\mathrm{Ca}^{2+}$ /calmodulin (CaM) (Hsu and Molday, 1993; Chen et al., 1994; Körschen et al., 1995). Electrophysiological analyses along with extensive biochemical characterization (Cook et al., 1987; Molday et al., 1990; Hsu and Molday, 1993; Körschen et al., 1995) suggest that the native rod channel is built exclusively from these two subunits.

The second subunit of the olfactory CNG channel has a much shorter N terminus than rod CNC $\beta 1$ a (Bradley et al., 1994; Liman and Buck, 1994) and phylogenetically is more closely related to $\alpha$ subunits than to CNC $\beta 1$ a (Kaupp, 1995). We therefore refer to this subunit as $\mathrm{CNC} \alpha 4$. Like CNC $\beta 1$ a from rod photoreceptors, $\mathrm{CNC} \alpha 4$ does not form functional $\mathrm{CNG}$ channels on its own, and when coexpressed with the $\mathrm{CNC} \alpha 3$ subunit it imparts flickery gating and increased cAMP sensitivity to the resultant heterooligomeric channel (Bradley et al., 1994; Liman and Buck, 1994). One caveat made clear in these papers concerns the cAMP sensitivity of the native olfactory channel (Frings et al., 1992), 
which still is more than twofold higher than that of $\mathrm{CNC} \alpha 3$ / $\mathrm{CNC} \alpha 4$ heteromers.

In a recent report, another subunit mRNA was identified that is expressed in rat olfactory epithelium (Sautter et al., 1998). This subunit represents an alternative splice form of the rod CNC $\beta 1 \mathrm{a}$ subunit and is referred to here as $\mathrm{CNC} \beta 1 \mathrm{~b}$. Coexpression of the CNC $\beta 1$ b-, $-\alpha 3$, and $-\alpha 4$ subunits produced channels that display a $K_{1 / 2}$ value for activation by cAMP similar to that of the native channel. Despite this similarity, it could not be concluded unequivocally that these subunits form the native channel in sensory cilia. For example, some subunits might be differentially targeted to the axon terminals in the olfactory bulb and may not be present in sensory cilia. Moreover, information on the properties of the native rat channel is sparse; in particular, no single-channel recordings are available. Here we examine the expression patterns of subunit mRNAs as well as the localization and association of the channel polypeptides in the rat olfactory epithelium. We find that all three subunit mRNAs are expressed in OSNs and that the three channel polypeptides are colocalized in the sensory cilia. For a functional assay of subunit composition, we performed a detailed single-channel analysis of the native CNG channel in rat OSNs. We then coexpressed the $\mathrm{CNC} \alpha 3-,-\alpha 4$, and $-\beta 1 \mathrm{~b}$ subunits in all possible combinations, looking for one combination that would resemble the native channel in all experimental parameters. The best match with respect to gating kinetics, singlechannel conductance, ion selectivity, and cAMP sensitivity was observed with channels containing all three subunits. Together these findings suggest that the native $\mathrm{CNG}$ channel in mature olfactory neurons is built from the $\mathrm{CNC} \alpha 3-,-\alpha 4$, and $-\beta 1 \mathrm{~b}$ subunits.

\section{MATERIALS AND METHODS}

Reverse transcription PCR and construction of complete cDNA clone. Cloning of cDNA encoding a CNG channel $\beta$ subunit from olfactory neurons was accomplished in two steps. Degenerate PCR primers were designed corresponding to segments in the N-terminal region, the transmembrane regions (S1-S6), and the cyclic nucleotide-binding region of the $\beta$ subunit from bovine rod photoreceptors. These primers were used in PCR reactions together with first-strand cDNA transcribed from poly $\left(\mathrm{A}^{+}\right) \mathrm{RNA}$ from rat olfactory epithelium (OE). Primer pair 476/477 (AARTAYATGGCNTTYTT, positions 1147-1163; CATRTCRAADATCATYTG, positions 1750-1767) amplified a segment between S4 and the beginning of the cGMP-binding site; primer pair 1451/1452 (AARGARCGNACNGARAARGT, positions 571-590; CCARCARTTCCARTTCCA, positions 844-862) amplified a segment between a putative CaM-binding site in the N-terminal region and $\mathrm{S} 1$; and primer pair 1477/1476 (TGACGTCACCTCCGATGAGG, positions 612-631; GTAGGCTTTGCTGAGGATGG, positions 1187-1206) amplified a segment between the CaM-binding site and S5. The $5^{\prime}$ and $3^{\prime}$ ends of the cDNA were obtained by the rapid amplification of cDNA ends (RACE) technique (Frohman et al., 1988) using gene-specific primers 1489 and 1490 (TTCTACAAGATCCCCCAGGTC, positions 1556-1580, and TGGTTCAGCTTCCGGACAAGATGCG, positions 1655-1689) for the 3' extension, and primers 1494 and 1495 (ACCACGAAGAACAGCCACAGGATG, positions 813-836, and TGAGGTTGGTCAGTGGGTCGATGC, positions 785-808) for the $5^{\prime}$ extension. The final clone, CNC $\beta 1 \mathrm{~b}$, was constructed from overlapping PCR fragments.

To distinguish in retinal cDNA between the photoreceptor and olfactory splice variants $C N C \beta 1 \mathrm{a}$ and $\mathrm{CNC} \beta 1 \mathrm{~b}$, we used two primer pairs corresponding to sequences directly $5^{\prime}$ (primer pair 2066/1526: GCTCCATCCGTCGCCTG, positions 206-222 and 813-829) and directly $3^{\prime}$ (primer pair 2067/1526: GTACCAGCCACGAAAGAG, positions 223240; AGAACAGCCACAGGATG, positions 813-829) to the splice site.

In situ hybridization. In situ hybridization was performed with sections from 3-week-old Sprague Dawley rats. The procedure, a modification of the protocol of Schaeren-Wiemers and Gerfin-Moser (1993), as well as the RNA probes against $\mathrm{CNC} \alpha 1, \mathrm{CNC} \alpha 3, \mathrm{CNC} \alpha 4$, SCG10, and I7, have been described previously (Bradley et al., 1997). The probe directed against the $3^{\prime}$ region in common between retinal $\mathrm{CNC} \beta 1$ a and olfactory $\mathrm{CNC} \beta 1 \mathrm{~b}$ (608 nucleotides), contains both $3^{\prime}$ untranslated sequences and sequences encoding the $129 \mathrm{C}$-terminal residues of the channel. The probe specific for olfactory $\mathrm{CNC} \beta 1 \mathrm{~b}$ corresponds to the first $3625^{\prime}$ untranslated nucleotides of the short form of the CNC $\beta 1 \mathrm{~b}$ cDNA. There is no significant homology between any of the channel subunit probes used. We showed directly by in situ hybridization to HEK 293 cells, transiently expressing high levels of each of the channel mRNAs, that the probes did not cross-hybridize under our hybridization conditions (data not shown). A positive signal is indicated by the purple enzymatic reaction product of the alkaline phosphatase (AP) reaction on the substrate nitro-blue tetrazolium. Development times were kept equal for all the probes relative to a given tissue ( $30 \mathrm{hr}$ for olfactory epithelium and $4 \mathrm{hr}$ for retina). To ascertain that the patterns observed for retinal and olfactory channel mRNAs are bona fide, we used, in parallel, antisense probes directed against the transcription factor SCG10 and the olfactory receptor $\mathrm{I7}$, respectively. The SCG10 probe specifically labeled ganglion cells, whereas the I7 signal was restricted to a subset of OSNs in a discrete ventral zone of the sensory epithelium (data not shown) (cf. Vasser et al., 1993), confirming the validity of our in situ hybridization procedure.

RNase protection assay. Total RNA was isolated from freshly dissected olfactory turbinates or eyes (postnatal day 18 male Wistar rat) by extraction with TRIzol (Life Technologies/BRL). The levels of the various CNC mRNA transcripts were determined by RNase protection (Ambion, HybSpeed RPA) according to the manufacturer's protocol. Briefly, ${ }^{32} \mathrm{P}$ labeled antisense RNA probes were synthesized in the presence of $\left[\alpha-{ }^{32} \mathrm{P}\right]-\mathrm{UTP}$ by transcription in vitro, from subcloned PCR products (Invitrogen). Mixtures of $\sim 90 \mathrm{ng}$ of a CNC probe $(\sim 30,000 \mathrm{cpm}$, specific activity $3.5 \times 10^{8} \mathrm{cpm} / \mu \mathrm{g}$ ) and $\sim 300 \mathrm{ng}$ of glyceraldehyde-3-phosphatedehydrogenase (GAPDH) probe $\left(\sim 7500 \mathrm{cpm}\right.$, specific activity $2.5 \times 10^{7}$ $\mathrm{cpm} / \mu \mathrm{g})$ were hybridized to yeast tRNA $(50 \mu \mathrm{g})$, with or without added olfactory or eye target RNA $(15 \mu \mathrm{g})$. After hybridization, the unhybridized sequences were digested with a mixture of RNases $\mathrm{A}$ and $\mathrm{T} 1$, then separated by electrophoresis on a 5\% polyacrylamide/7 M urea sequencing gel. For the controls of yeast RNA alone and no RNase digestion (lanes 11-15), only one-tenth of the total reaction was loaded. The gel was then dried and exposed to x-ray film without an intensifying screen. The probes used for detection of the various CNC subunit mRNAs were as follows. The 195 nucleotide $\mathrm{CNC} \alpha 4$ probe protects a band of 126 nucleotides and spans base pairs 2127-2253 (GenBank U12623); the 282 nucleotide $\mathrm{CNC} \beta 1 \mathrm{~b}$ probe protects a band of 213 nucleotides and spans base pairs $642-855$ (GenBank AF068572); the 271 nucleotide CNC $\alpha 1$ probe protects a band of 200 nucleotides and spans base pairs $2415-2577$ (GenBank X55519); the 328 nucleotide pan- $\beta$ probe protects a band of 260 nucleotides and spans base pairs 3066-3326 (GenBank AF068572); and the 102 nucleotide rat GAPDH probe protects a band of 68 nucleotides and spans base pairs 575-644 (GenBank M17701). For quantifying the bands, the dried gel was exposed to a phosphorimager plate and analyzed with the TINA program package (v2.09) for the BAS-Reader series of Fuji Image Plate scanners (BAS1000). After quantifying, the bands representing protection of channel probes were corrected for uridine content and normalized to the loading control, GAPDH.

Membrane protein preparation. Rat olfactory epithelium was homogenized in a glass/Teflon homogenizer in ice-cold $10 \mathrm{mM}$ HEPES, $0.1 \mathrm{~mm}$ EGTA, $1 \mathrm{~mm}$ DTT, $5 \mu \mathrm{g} / \mathrm{ml}$ aprotinin, $5 \mu \mathrm{g} / \mathrm{ml}$ leupeptin, $1 \mu \mathrm{g} / \mathrm{ml}$ pepstatin, $500 \mu \mathrm{g} / \mathrm{ml}$ Pefabloc SC (Boehringer Mannheim, Mannheim, Germany), $10 \mathrm{~mm}$ benzamidine, $\mathrm{pH}$ 7.5. The suspension was washed twice by centrifugation at $100 \times g$ for $7 \min \left(4^{\circ} \mathrm{C}\right)$ to separate the membranes from nuclei. Membranes were collected by centrifugation at $21,000 \times g$ for $30 \mathrm{~min}\left(4^{\circ} \mathrm{C}\right)$. The membrane pellet was resuspended in 10 mM HEPES, $500 \mathrm{~mm} \mathrm{NaCl}, 0.1$ mm EGTA, 1 mм DTT, pH 7.5 (plus protease inhibitors), washed by centrifugation, and resuspended in cold $10 \mathrm{~mm}$ HEPES, $100 \mathrm{~mm} \mathrm{NaCl}, 0.1 \mathrm{~mm}$ EGTA, $1 \mathrm{~mm}$ DTT, pH 7.5. Membrane proteins from transfected and nontransfected HEK 293 cells were isolated by the same procedure.

Isolation of olfactory cilia. Olfactory cilia preparations were obtained using the calcium-shock method (Anholt et al., 1986; Chen et al., 1986). Briefly, after a short wash of the olfactory epithelium in ice-cold saline solution ( $120 \mathrm{~mm} \mathrm{NaCl}, 5 \mathrm{~mm} \mathrm{KCl}, 1.6 \mathrm{~mm} \mathrm{~K}_{2} \mathrm{HPO}, 25 \mathrm{~mm} \mathrm{NaHCO}_{3}, 7.5$ $\mathrm{mm}$ glucose, $\mathrm{pH}$ 7.4), the tissue was subjected to Ringer's solution containing $10 \mathrm{~mm}$ calcium and gently stirred for $5 \mathrm{~min}$ at $4^{\circ} \mathrm{C}$. Detached cilia were isolated by three sequential centrifugation steps for $5 \mathrm{~min}$ at $7700 \times g$. The supernatants containing the cilia were collected, and pellets were resuspended in Ringer's solution containing $10 \mathrm{~mm} \mathrm{CaCl}_{2}$ as 
described above. The cilia preparation was obtained after a final centrifugation step of all the pooled supernatants for $15 \mathrm{~min}$ at $27,000 \times \mathrm{g}$. The pellet containing the cilia was resuspended in hypotonic buffer $(10 \mathrm{mM}$ Tris, $3 \mathrm{~mm} \mathrm{MgCl}_{2}, 2 \mathrm{~mm}$ EGTA, $\mathrm{pH}$ 7.4) and stored at $-70^{\circ} \mathrm{C}$. The yield of cilia was $\sim 0.5 \mathrm{mg}$ per rat.

Western blot analysis. Protein amounts for ciliary and epithelial preparations were determined in parallel on one filter according to Schaffner and Weissmann (1973). From each preparation, $15 \mu \mathrm{g}$ were separated by SDS-PAGE, transferred to Immobilon-P membrane (Millipore), which was blocked with $0.5 \%$ milk powder in PBS, and sequentially probed with the following purified primary antibodies: mouse anti- $\alpha 4$ 1:30 [mAB7B11, directed against residues 392-575 of CNC $\alpha 4$ (Bradley et al., 1997)]; rabbit anti- $\beta 1$ a 1:500 [polyclonal FPc21K, directed against residues 574-763 representing the N-terminal domain of the $\beta^{\prime}$ part of retinal CNC $\beta 1$ a (Körschen et al., 1995; Wiesner et al., 1998)]; rabbit anti- $\alpha 3$ 1:150 [polyclonal, directed against residues 559-664 of CNC $\alpha 3$ (Bradley et al., 1997)]; and rabbit anti-ACIII 1:500 (Santa Cruz Biotechnology) directed against the olfactory adenylyl cyclase type III. Appropriate secondary antibodies were HRP-coupled and detected by enhanced chemiluminescence (Amersham).

For deglycosylation, membrane proteins were first denatured in the presence of $0.5 \% \mathrm{SDS} / 1 \% 2$-mercaptoethanol for $10 \mathrm{~min}$ at room temperature and then incubated in $50 \mathrm{~mm} \mathrm{PBS} / 1 \% \mathrm{NP}-40$ and $500 \mathrm{U}$ of peptide/N-glycosidase $\mathrm{F}$ (NEB) for $2 \mathrm{hr}$ at $37^{\circ} \mathrm{C}$.

Immunohistochemistry. Three-week-old rats (Sprague Dawley) were anesthetized with fluothane and quickly decapitated. The rostral part of the skull, containing the nasal cavity, was dissected and immersed in $4 \%$ paraformaldehyde $/ 0.1 \mathrm{~m}$ phosphate buffer $(\mathrm{PB}), \mathrm{pH} 7.4$, for $1 \mathrm{hr}$. To enable access of the fixative to the olfactory epithelium, the air was evacuated from the nasal cavity in a low-pressure chamber for a few minutes. After several rinses in PB, tissue was cryoprotected in $30 \%$ sucrose in PB overnight. The next day, tissue was embedded in OCT compound (Miles Scientific) and frozen onto the cryostat stage. Coronal sections (16 $\mu \mathrm{m}$ thick) were cut on a cryostat (Reichert \& Jung) and collected on gelatin-coated slides. Sections were air-dried, post-fixed in $4 \%$ paraformaldehyde for $5 \mathrm{~min}$, washed in $\mathrm{PB}$, and incubated in $10 \%$ normal goat serum (NGS), $0.5 \%$ Triton X-100 in PB for $1 \mathrm{hr}$. Primary antibodies were diluted in 5\% NGS, $0.5 \%$ Triton $\mathrm{X}-100,0.05 \% \mathrm{NaN}_{3}$ in PB. Purified antibody directed against $\mathrm{CNC} \alpha 3$ was diluted 1:500; purified antibody FPc21K directed against CNC $\beta 1$ a was diluted 1:1000; monoclonal antibody mAB7B11 (Bradley et al., 1997) was diluted 1:5; antiACIII was diluted 1:1000. Sections were incubated with primary antibodies for several hours or overnight at room temperature. After several rinses in $\mathrm{PB}$, sections were incubated with biotinylated secondary antibodies (Sigma; anti-rabbit-biotin 1:1000 or anti-mouse-biotin 1:80) diluted in 5\% NGS, $0.5 \%$ Triton X-100 for $1.5 \mathrm{hr}$. Sections were rinsed in PB and subsequently incubated with Extravidin-HRP (Sigma; 1:300 dilution in $\mathrm{PB}$ ) for $1.5 \mathrm{hr}$. After several rinses in $\mathrm{PB}$, immunoreactivity was visualized using diaminobenzidine (DAB) as chromogen $(0.05 \%$ DAB, $0.01 \% \mathrm{H}_{2} \mathrm{O}_{2}$ in $\left.\mathrm{PB}\right)$. Sections were coverslipped with Mowiol solution (Hoechst) and photographed using differential interference contrast optics.

Electrophysiological experiments. Rat OSNs were isolated from 3- to 6-week-old Sprague Dawley rats as described previously (Frings et al., 1992). After isolation the olfactory epithelium was washed in a solution containing (in mM): $145 \mathrm{NaCl}, 5 \mathrm{KCl}, 10 \mathrm{HEPES}, 10$ glucose, adjusted to $\mathrm{pH} 7.4$ with $\mathrm{NaOH}$. After dissection into small pieces, the tissue was incubated for $40 \mathrm{~min}$ in the same solution containing $0.2 \mathrm{mg} / \mathrm{ml}$ trypsin at $37^{\circ} \mathrm{C}$. After trituration, the cell suspension was transferred to the recording chamber. Isolated OSNs were identified by their characteristic morphology and investigated with the patch-clamp technique (Hamill et al., 1981) using a LIST PC amplifier (LIST, Darmstadt, Germany). Macroscopic recordings were obtained from membrane patches excised from dendritic knobs, and single-channel recordings were obtained from the membrane of somata and dendrites (Frings et al., 1992). Expression of cloned cDNAs encoding the $\mathrm{CNC} \alpha 3, \mathrm{CNC} \alpha 4$, and $\mathrm{CNC} \beta 1 \mathrm{~b}$ subunits in HEK 293 cells was performed as described previously (Bönigk et al., 1993; Baumann et al., 1994). Transient expression was driven by insertion of cDNAs into pCIS (Genentech; $\mathrm{CNC} \alpha 3$ and $\mathrm{CNC} \alpha 4$,) or pcDNAIamp (Invitrogen; $\mathrm{CNC} \beta 1 \mathrm{~b}$ ).

The solutions for cotransfection contained the following approximate molar ratios of plasmids: $\mathrm{CNC} \alpha 3 / \mathrm{CNC} \alpha 4=4: 1 ; \mathrm{CNC} \alpha 3 / \mathrm{CNC} \alpha 4$ / $\mathrm{CNC} \beta 1 \mathrm{~b}=2: 1: 2$. The combination $\mathrm{CNC} \alpha 3 / \mathrm{CNC} \beta 1 \mathrm{~b}$ was tested at the ratios 3:7,1:1, and 7:3. CNC $\alpha 4$ and $\mathrm{CNC} \beta 1 \mathrm{~b}$ were tested with $1: 1$ and 7:3 mixtures. We did not observe any difference in the expression pattern of $\alpha 3 \beta 1 \mathrm{~b}$ channels using these three different plasmid ratios. Single-channel currents were recorded from inside-out patches excised from the membrane of cells expressing the respective subunits. The solution in the recording pipette contained (in $\mathrm{mM}$ ): $120 \mathrm{NaCl}, 3 \mathrm{KCl}, 10$ HEPES, 10 EGTA, adjusted to $\mathrm{pH} 7.4$ with $\mathrm{NaOH}$. For experiments under symmetrical ionic conditions, the same solution was used on both sides of the patch. The bath solution for bi-ionic experiments contained (in mM): 120 $\mathrm{KCl}, 5 \mathrm{NaCl}, 10 \mathrm{HEPES}, 10 \mathrm{EGTA}$, adjusted to $\mathrm{pH} 7.2$ with $\mathrm{KOH}$. cAMP concentrations were determined spectrophotometrically. Steadystate macroscopic currents were digitized and recorded at $50 \mathrm{~Hz}$ (PhoCal, Life Science Resources, Cambridge, UK); Macroscopic $I-V_{\mathrm{m}}$ relations were sampled at $1 \mathrm{kHz}$ (PhoClamp, Life Science Resources). After currents were measured at various cAMP concentrations, leak currents were subtracted. Dose-response relations were constructed for each patch by fitting to the data a Hill-type function, $I / I_{\max }=c^{\mathrm{n}} /\left[c^{\mathrm{n}}+K_{1 / 2}{ }^{\mathrm{n}}\right]$, where $I_{\max }$ is the current at saturating concentrations of the ligand, $c$ is the ligand concentration, $n$ is the Hill coefficient, and $K_{1 / 2}$ is the concentration for half-maximal channel activation. The mean values for $K_{1 / 2}$ and $n$ from all patches were used to construct the solid lines in the doseresponse plots. The Figures also show the mean values of $I / I_{\max }$ for each concentration with SDs. Results in the text, are given as means \pm SD, with numbers of experiments in parentheses. Single-channel currents were recorded with a filter frequency of $5 \mathrm{kHz}$ (eight-pole Bessel filter) on a DAT recorder (DTR-1202, Biological). The data were digitized at $3 \mathrm{kHz}$ and filtered at $1 \mathrm{kHz}$ for analysis (PAT, Life Science Resources). Single-channel current and open probability were determined from allpoint amplitude histograms obtained from single-channel recordings of $20-50 \mathrm{sec}$ duration. Single-channel currents were obtained from the difference in open and closed peaks, whereas open probability was derived from the fractional area of the open peak. Amplitude histograms in the Figures display on the ordinate the percentage of the total recorded time spent in each current level indicated on the abscissa.

\section{RESULTS}

\section{Cloning of CNC $\beta 1 b$, a CNG channel $\beta$ subunit from rat olfactory neurons}

The cDNA encoding rat $\mathrm{CNC} \beta 1 \mathrm{~b}$ was cloned by RT-PCR using degenerate primers derived from sequences of CNC $\beta 1 \mathrm{a}$, the $\beta$ subunit of rod photoreceptors (Chen et al., 1994; Körschen et al., 1995). The $5^{\prime}$ and $3^{\prime}$ ends of the cDNA were obtained by the RACE technique. Overlapping PCR fragments were used to generate the final recombinant clone encoding the rat olfactory $\beta$ subunit, termed CNC $\beta 1 \mathrm{~b}$. As shown in Figure 1, CNC $\beta 1 \mathrm{~b}$ codes for a protein of 858 amino acid residues with a calculated molecular mass of $96.4 \mathrm{kDa}$ and high sequence similarity to the $\beta$ subunit from rod photoreceptors $(\mathrm{CNC} \beta 1 \mathrm{a})$. The $\mathrm{CNC} \beta 1 \mathrm{~b}$ sequence from residues $75-858$ shares $87.5 \%$ amino acid identity with bovine rod $\mathrm{CNC} \beta 1 \mathrm{a}$ and $100 \%$ with rat $\mathrm{CNC} \beta 1 \mathrm{a}$, whereas the $\mathrm{N}$-terminal sequence from residues $1-74$ is entirely different. One obvious implication of such a large domain of identity is that olfactory $\mathrm{CNC} \beta 1 \mathrm{~b}$ and retinal $\mathrm{CNC} \beta 1 \mathrm{a}$ are derived from the same gene by alternative splicing.

The CNC $\beta 1$ a polypeptide is much larger than $\mathrm{CNC} \beta 1 \mathrm{~b}$ (calculated molecular mass: $155 \mathrm{kDa}$ vs $96.4 \mathrm{kDa}$ ) and is characterized by an unusual bipartite structure (Körschen et al., 1995). The $\mathrm{C}$-terminal half (referred to as the $\beta^{\prime}$ part) shows significant structural similarity to $\alpha$ subunits, whereas the large N-terminal half is nearly identical to a glutamic acid-rich protein (referred to as the GARP part). It has been shown that residues G571/V572 (corresponding to V75 in $\mathrm{CNC} \beta 1 \mathrm{~b}$ ) mark the boundary between the GARP part and the $\beta^{\prime}$ part of bovine CNC $\beta 1$ a (Fig. 1, arrowhead) (Körschen et al., 1995). In addition, an intron interrupts the genomic sequence in the human $\mathrm{CNC} \beta$ gene at this site (Ardell et al., 1996). In accordance with the gene-structure analysis of CNC $\beta 1$ presented by Sautter et al. (1998) and our own RNase protection assays (see Fig. 3), we conclude that olfactory $\mathrm{CNC} \beta 1 \mathrm{~b}$ and rod $\mathrm{CNC} \beta 1 \mathrm{a}$ are derived from alternatively spliced $\mathrm{CNC} \beta$ transcripts. 


\section{Detection of CNC $\alpha 3,-\alpha 4$, and - $\beta 1 \mathrm{~b}$ mRNA in olfactory neurons}

We performed in situ hybridization of digoxigenin-labeled antisense RNA probes to $20 \mu \mathrm{m}$ cryostat sections. Probes were directed against nonconserved regions (mostly nontranslated sequences) of the subunits and detected with an AP-conjugated anti-digoxigenin antibody. Expression of the olfactory CNC $\beta 1 \mathrm{~b}$ subunit message in sections of olfactory epithelium is clearly detected in the sensory neurons using a probe directed against the olfactory-specific $5^{\prime}$ region of CNC $\beta 1 \mathrm{~b}$ mRNA (Fig. $2 A$ ), and by a probe that hybridizes to the common $3^{\prime}$ region of olfactory and retinal $\beta$ messages (Fig. $2 B$ ). The AP reaction product respects the respiratory/sensory epithelial border (Fig. $2 A$, arrow), indicating specific expression in OSNs. As a control, expression of CNC $\alpha 1$ mRNA was not detected in OSNs, but in the retina (Fig. 2, compare $C, H$ ). As judged by the intensity of the AP product, the level of expression of CNC $\beta 1 \mathrm{~b}$ in OSNs is similar to that of $\mathrm{CNC} \alpha 3$ (Figs. 2, compare $A, B$, and $E$ ). The expression levels of $\mathrm{CNC} \alpha 3$ and $\mathrm{CNC} \beta 1 \mathrm{~b}$ message appeared to be higher than that of CNC $\alpha 4$ (Figs. 2, compare $E, A$, and $D$ ) (cf. Bradley et al., 1994). For direct comparison, the color reactions in Figure $2 A-E$ have been developed for the same time. Five times longer development time of the $\mathrm{CNC} \alpha 4$ signal resulted in a staining intensity similar to that seen with $\mathrm{CNC} \beta 1$ b- or $\mathrm{CNC} \alpha 3$-specific probes (data not shown). The very weak signal of the $\mathrm{CNC} \alpha 4$ probe possibly reflects a lower expression level of $\mathrm{CNC} \alpha 4$ mRNA. We have confirmed this observation by performing quantitative RNase protection assays (see below).

To distinguish between olfactory and retinal splice variants of $\beta$ subunit mRNA, we performed hybridizations to sections of rat retina with both the olfactory $\mathrm{CNC} \beta 1$ b-specific 5' probe, and the probe directed against the common $3^{\prime}$ region of $\mathrm{CNC} \beta 1 \mathrm{a}$ and CNC $\beta 1$ b. As expected, the common $3^{\prime}$ probe, detected expression of $\mathrm{CNC} \beta 1 \mathrm{a}$ in retinal photoreceptors as indicated by the reaction product localized to the inner segments of these cells (Fig. 2G). The 5' probe did not produce any signal in the retina (Fig. $2 F$ ), confirming that the $\beta$ subunit mRNA exists in at least two splice forms, one in retinal rod photoreceptors (CNC $\beta 1 \mathrm{a})$ and one in olfactory sensory neurons $(\mathrm{CNC} \beta 1 \mathrm{~b})$.

\section{Quantitative analysis of CNC $\alpha$ and $\beta$ mRNA expression}

The expression levels of the various subunit transcripts were analyzed by quantitative RNase protection assay to answer the following questions. We sought to clarify the nature of the weak $\mathrm{CNC} \alpha 4$ signal seen in our in situ hybridization, distinguishing whether-relative to the other CNC subunits-this signal represents a lower level of expression of $\mathrm{CNC} \alpha 4$ mRNA or is just an example of the nonquantitative nature of in situ hybridizations. We also wished to analyze the olfactory-specific use of the exon encoding the 74 amino acids unique to the $\mathrm{N}$ terminus of CNC $\beta 1$ b. Primers were designed for amplification of five short amplicons (126-260 bp in length) from the cDNA clones for CNC $\alpha 1,-\alpha 3,-\alpha 4$, and $-\beta 1 \mathrm{~b}$ (see Materials and Methods). These were subcloned and used as templates for transcribing $\left[\alpha-{ }^{32} \mathrm{P}\right]-$ UTP-labeled antisense probes against the CNC mRNA transcripts. For $\mathrm{CNC} \beta 1 \mathrm{~b}$, two probe templates were amplified. One amplicon was directed against the $3^{\prime}$ end of the cDNA to generate a pan- $\beta$ probe, which should detect all $\beta$ gene transcripts. The second amplicon spans the position of divergence between $\mathrm{CNC} \beta 1 \mathrm{~b}$ and $\mathrm{CNC} \beta 1 \mathrm{a}$ in their respective $5^{\prime}$ coding regions. Therefore, the antisense probe generated from this second $\beta 1 \mathrm{~b}$ template has 100 of 213 complementary bases in common with $\mathrm{CNC} \beta 1 \mathrm{a}$ and is entirely complementary to $\mathrm{CNC} \beta 1 \mathrm{~b}$.

The result of an RNase protection assay with these probes is shown in Figure 3. Each reaction contained two labeled probes, one complementary to a CNC subunit and a second used as a loading control complementary to GAPDH. The signals in lanes 11-15 (each one-tenth of a reaction with no RNase digestion) are stronger than or equal to those in lanes 1-10. Thus, we can be assured that the probes were in excess during the hybridization and that our results were quantitative. In lane 1 , the band migrating at 126 nucleotides represents the expression level of $\mathrm{CNC} \alpha 4$ mRNA in olfactory turbinates. The results confirm that the expression level of $\mathrm{CNC} \alpha 4$ mRNA in the olfactory turbinates is 6to 14 -fold lower than those of either $\mathrm{CNC} \alpha 3$ or $\mathrm{CNC} \beta 1 \mathrm{~b}$ (compare lane 1 with lanes 4 and 5). This result may explain the weak signal seen for $\mathrm{CNC} \alpha 4$ mRNA expression in the in situ hybridization (Fig. 2D). Corroborative support for a lower level of CNC $\alpha 4$ mRNA expression comes from results of screening an olfactory cDNA library for $\mathrm{CNC} \alpha 3$ and $\mathrm{CNC} \alpha 4$. The abundance of $\mathrm{CNC} \alpha 3$ clones was found to be $\sim 1$ in $10^{4}$, whereas $\mathrm{CNC} \alpha 4$ clones were 1 in $10^{5}$ (Bradley, 1996).

Turning to $\mathrm{CNC} \beta$ expression, lane 2 shows that 213 nucleotides of the CNC $\beta 1 \mathrm{~b}$ probe are protected when hybridized to the olfactory RNA. When hybridized to RNA from the eye (lane 7), the same probe protected a band of 100 nucleotides, as expected for detection of $\beta 1$ a expression in this tissue. Protection is also observed for a band of 120 nucleotides, suggesting that perhaps a short ( $\sim 20 \mathrm{bp}$ ) sequence of CNC $\beta 1 \mathrm{~b}\left(5^{\prime}\right.$ of the divergent point between $\mathrm{CNC} \beta 1 \mathrm{~b}$ and $\mathrm{CNC} \beta 1 \mathrm{a}$ ) is expressed as part of an mRNA in the eye. If both the 100 and 120 nucleotide bands in lane 7 represent $\beta$ gene mRNAs expressed in the eye, then their signals should sum to the signal of the 260 nucleotide band seen with the pan- $\beta$ probe (lane 10). After correction for the amount loaded (GAPDH signal) and the difference in length (i.e., uridine content), the signal of the 100 nucleotide band alone accounts for the 260 nucleotide pan- $\beta$ probe signal in lane 10 . Furthermore, in RT-PCR experiments with primers against the $\mathrm{CNC} \beta 1 \mathrm{~b}$ sequence $-5^{\prime}$ primer either just upstream or just downstream of the $\mathrm{CNC} \beta 1 \mathrm{~b} / \beta 1 \mathrm{a}$ divergence point, and a $3^{\prime}$ primer downstream in $\mathrm{CNC} \beta 1 \mathrm{~b}$-we were never able to detect expression of the CNC $\beta 1$ b-specific sequences in the eye (data not shown; and see Materials and Methods). Therefore, we conclude that the 120 nucleotide band protected with the $\mathrm{CNC} \beta 1 \mathrm{~b}$ probe in lanes 7 and 2 is an artifact of the assay. Lane 3 shows that there is no expression of $\mathrm{CNC} \alpha 1$ in the olfactory turbinates. Likewise, lanes 6 and 9 show that there is no expression of $\mathrm{CNC} \alpha 3$ or $\mathrm{CNC} \alpha 4$ in the eye. These reactions also serve as negative controls for our demonstration of $\beta$ expression in both the eye and olfactory tissue (lanes 5 and 10, respectively).

\section{Expression of all three subunits in sensory cilia}

The presence in OSNs of transcripts encoding all three channel subunits provides suggestive evidence but does not prove that the subunit polypeptides are expressed in sensory cilia. In particular, the low expression level of $\mathrm{CNC} \alpha 4$ message in OSNs raises the question to what extent the $\mathrm{CNC} \alpha 4$ protein contributes to the native channel in the sensory cilia. To examine this, we compared membrane protein extracts from whole OE (including cilia) to preparations of isolated cilia. Using the same amount of membrane protein from each preparation, proteins were separated by SDS-PAGE and analyzed by Western blotting and probing with subunit-specific antibodies. As control for the purity of our cilia 


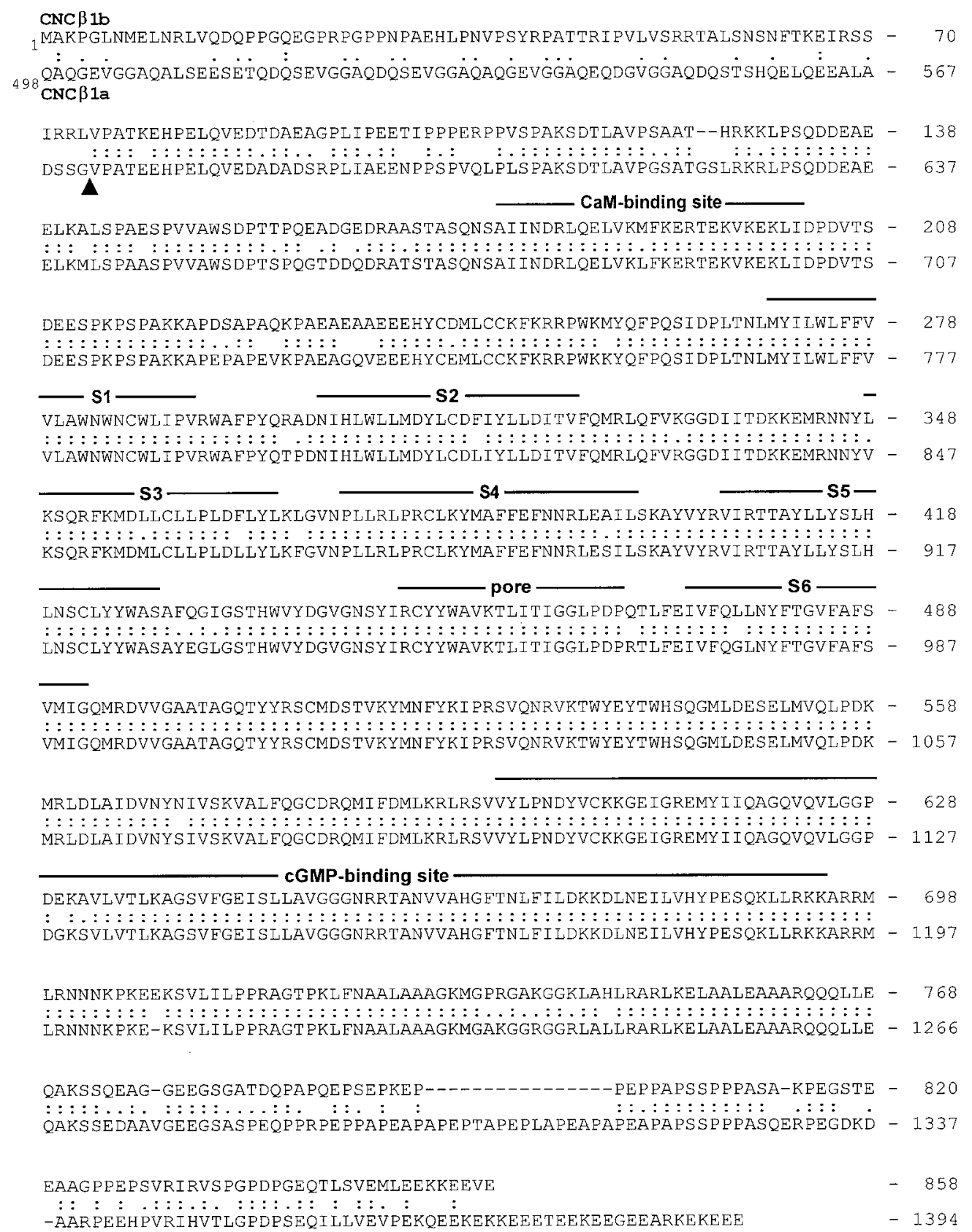

Figure 1. Alignment of the deduced amino acid sequence of rat olfactory $\mathrm{CNC} \beta 1 \mathrm{~b}$ with bovine rod CNC $\beta 1 \mathrm{a}$. Numbers indicate positions of amino acid residues in the polypeptide. The sequence of CNC $\beta 1 \mathrm{a}$ is presented starting at residue 498. Colons and periods between the two sequences indicate identical residues and conservative substitutions, respectively. Structural features similar to those of $\alpha$ subunits are represented by lines above the sequence. S1-S6, Membrane-spanning segments; S4, voltage sensor-like motif; $P$, the pore motif that lines the cavity of the channel; CaM, a nonconventional calmodulin-binding site (Weitz et al., 1998). Arrowhead indicates an exon boundary identified in human rod CNC $\beta 1$ a (Ardell et al., 1996).

preparation, we used an antibody directed against adenylyl cyclase type III (ACIII). ACIII has been proposed to mediate the odorant-induced rise of cAMP in OSNs and is localized to cilia (Pace et al., 1985; Pfeuffer et al., 1989; Bakalyar and Reed, 1990; Menco et al., 1992). Figure $4 A$ demonstrates that ACIII $(\sim 230$ $\mathrm{kDa}$ ), in fact, is highly enriched in purified cilia (lane 2) compared with whole OE (lane 1). In membranes from whole OE, a polyclonal antibody raised against the rat $\mathrm{CNC} \alpha 3$ subunit (Bradley et al., 1997) recognized a faint band of $\sim 75 \mathrm{kDa}$ and a diffuse "smear" at 110-145 kDa (Fig. 4B, lane 1). In purified cilia, both the smear and the $75 \mathrm{kDa}$ band were greatly enriched (Fig. $4 B$, lane 2). The $\mathrm{CNC} \alpha 3$ polypeptide, expressed in HEK 293 cells, had almost the same size as the $75 \mathrm{kDa}$ signal in cilia (Fig. $4 B$, compare lanes 2 and 5), suggesting that this band indeed represents the $\mathrm{CNC} \alpha 3$ subunit. With some cilia preparations, however, the $75 \mathrm{kDa}$ band was not enriched or was even less intensely labeled compared with whole OE preparations. On the other hand, the "smear" was always enriched in cilia membranes over whole OE membranes. We were concerned about this result because (1) it would indicate that the majority of the $\mathrm{CNC} \alpha 3$ protein is not in cilia, and (2) the pronounced smear, if caused by unspecific cross-reactivity, would render suspect any immunohis- 



Figure 2. Cell type-specific expression of $\mathrm{CNC} \alpha 3,-\alpha 4$, and $-\beta 1 \mathrm{~b}$ mRNAs in the olfactory epithelium. In situ hybridization analysis of olfactory channel subunits expressed in rat olfactory epithelium $(A-E)$ and retina $(F-H)$. Expression of channel mRNA was examined in $20-\mu$ m-thick sections using digoxigenin-labeled antisense RNA probes against nonconserved regions of each subunit. Visualization was achieved with an AP-conjugated antidigoxigenin antibody. A positive signal is indicated by a purple AP reaction product. Shown are signals with probes against $(A, F)$ the olfactory specific $5^{\prime}$ region of $\mathrm{CNC} \beta 1 \mathrm{~b},(B, G)$ the $3^{\prime}$ region in common with CNC $\beta 1$ a and $\mathrm{CNC} \beta 1 \mathrm{~b},(C, H) \mathrm{CNC} \alpha 1,(D) \mathrm{CNC} \alpha 4$, and $(E) \mathrm{CNC} \alpha 3$. Arrows in $A$ mark the transition zone between olfactory epithelium $(O E)$ and respiratory epithelium $(R E)$. Positive signals correspond to expression in olfactory sensory neurons $(O S N)$, not supporting cells $(S C)$ or basal cells $(B C)$. In $F-H$, positive signals are restricted to the inner segment (IS) layer of photoreceptors; other layers are outer segments $(O S)$, outer nuclear layer $(O N L)$, outer plexiform layer $(O P L)$, inner nuclear layer $(I N L)$, inner plexiform layer $(I P L)$, and ganglion cell layer $(G C L)$. Scale bars, $50 \mu \mathrm{m}$.

tochemical localization with anti- $\alpha 3$ antibody. We tested whether glycosylation of $\mathrm{CNC} \alpha 3$ or formation of a stable complex with other ciliary components explains the fuzzy $110-145 \mathrm{kDa}$ signal. Several treatments known to dissociate protein complexes were ineffective in reducing the smear signal (data not shown). In contrast, treatment of whole OE (lane 3) and cilia preparations (lane 4) with glycosidase abolished the diff use smear entirely and strongly enhanced the $75 \mathrm{kDa}$ signal. Before glycosidase treatment, the weak $75 \mathrm{kDa}$ band in cilia consistently exhibited a slightly lower electrophoretic mobility than the $75 \mathrm{kDa}$ band after deglycosylation (Fig. 4B, compare lane 2 with lanes 3, 4, 5). This minor difference may indicate that even the $\sim 75 \mathrm{kDa}$ form is glycosylated, although to a much lower degree. These results demonstrate that the vast majority of the $\mathrm{CNC} \alpha 3$ polypeptide exists in a highly glycosylated form. In our cilia preparations, we observed batch to batch variation in the intensity of the $75 \mathrm{kDa}$ band relative to preparations from whole OE, whereas the smear was always enhanced. It therefore seems likely that the glycosylated form is specifically targeted to cilia, whereas the nonglycosylated form might be expressed elsewhere in OSNs, for example the soma.

Enrichment of subunit polypeptide is also observed using monoclonal antibody mAB7B11 directed against the $\mathrm{CNC} \alpha 4$ protein (Fig. 4C) (Bradley et al., 1997). We observed a much stronger signal with isolated cilia than with whole OE membranes
(Fig. 4C, lanes 1 and 2). The apparent molecular mass of $\mathrm{CNC} \alpha 4$ $(\sim 62 \mathrm{kDa})$ in cilia (lane 2) is identical with the apparent molecular mass of the subunit expressed in HEK 293 cells (lane 3) and matches well the calculated molecular mass $(65.7 \mathrm{kDa})$. No other proteins were stained by this antibody. These data show that $\mathrm{CNC} \alpha 4$ is expressed in olfactory cilia and that the molar concentration of this subunit (relative to the total protein content) is higher in cilia than in nonciliary membranes.

Polyclonal antibody FPc21K, directed against $\mathrm{CNC} \beta 1 \mathrm{~b}$, also demonstrated enrichment of the $\beta$ subunit in ciliary membranes (Fig. 4D, lanes 2 and 3). The apparent molecular mass of $\mathrm{CNC} \beta 1 \mathrm{~b}$ is significantly larger than predicted from the amino acid sequence $(\sim 116 \mathrm{kDa}$ vs $96.4 \mathrm{kDa})$. A similar difference was reported for the $\beta^{\prime}$ part of bovine CNC $\beta 1$ a, which comprises the region common to both $C N C \beta 1 \mathrm{a}$ and $\mathrm{CNC} \beta 1 \mathrm{~b}$ (apparent: 110 $\mathrm{kDa}$; calculated: $92.7 \mathrm{kDa}$ ) as well as for the complete retinal CNC $\beta 1$ a subunit (apparent: $240 \mathrm{kDa}$; calculated: $155 \mathrm{kDa}$ ) (Körschen et al., 1995). The olfactory $\mathrm{CNC} \beta 1 \mathrm{~b}$, like the retinal CNC $\beta 1$ a subunit, is susceptible to proteolytic degradation (W. Bönigk, unpublished observations). The smaller size of CNC $\beta 1 \mathrm{~b}$ expressed in HEK 293 cells is probably caused by proteolysis (Fig. 4D, lane 3). Glycosidase treatment had no effect on the electrophoretic mobility of $\mathrm{CNC} \alpha 4$ and $\mathrm{CNC} \beta 1 \mathrm{~b}$, demonstrating that these subunits are not glycosylated (data not shown).

We used immunohistochemistry to localize CNG channel sub- 


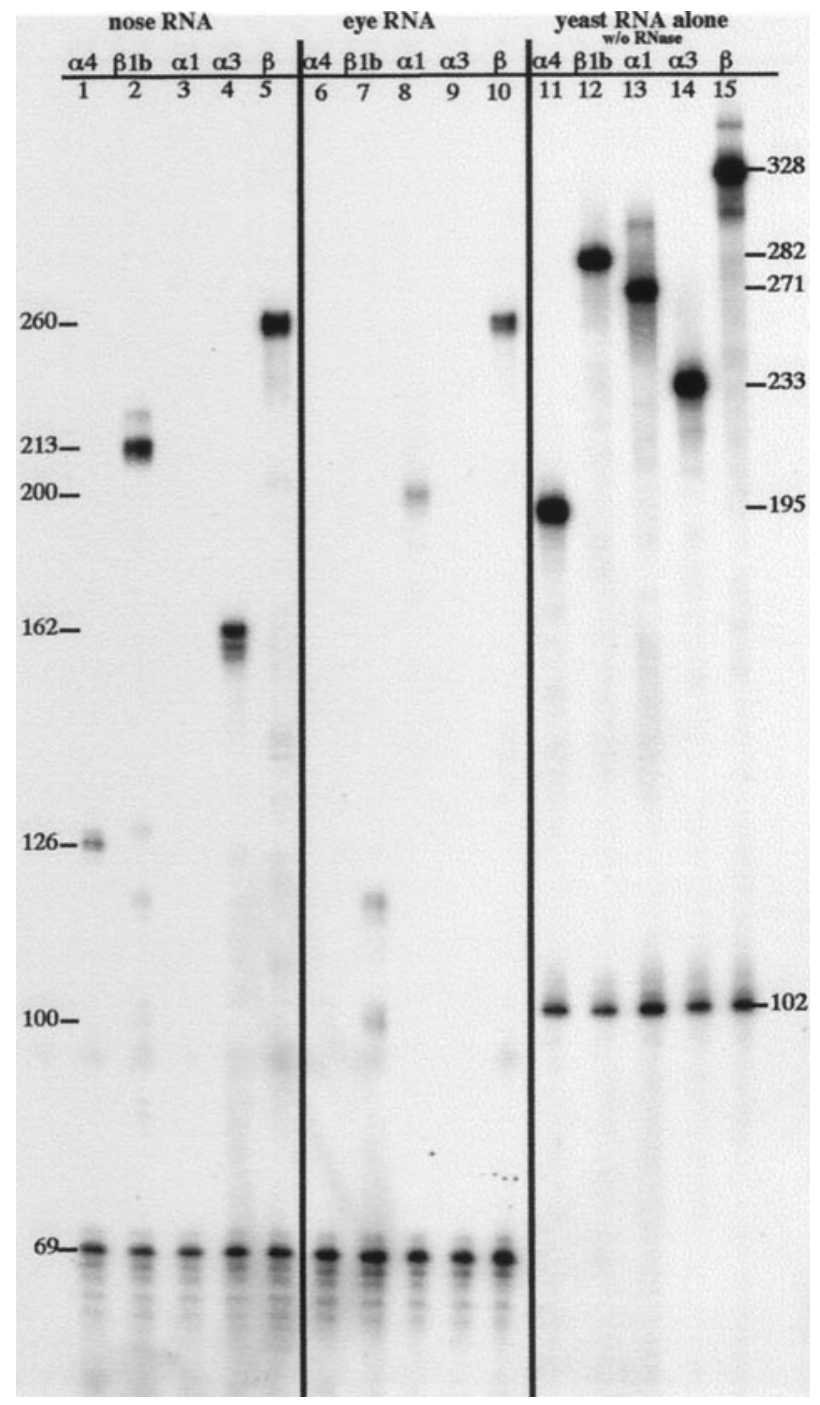

Figure 3. Analysis of $\mathrm{CNC} \alpha$ and $\beta$ mRNA expression by RNase protection. ${ }^{32} \mathrm{P}$-labeled antisense RNA probes were hybridized to total RNA from olfactory or eye tissue, subjected to RNase digestion, and resolved on a sequencing gel. Left panel, lanes 1-5, Protection of probes for GAPDH and CNC subunits $\alpha 4, \beta 1 \mathrm{~b}, \alpha 1, \alpha 3$, and $\beta$ by olfactory RNA. Center panel, lanes 6-10, Protection of probes for GAPDH and CNC subunits $\alpha 4, \beta 1 \mathrm{~b}, \alpha 1, \alpha 3$, and $\beta$ by eye RNA. Right panel, lanes 11-15, Probes for GAPDH and CNC subunits $\alpha 4, \beta 1 \mathrm{~b}, \alpha 1, \alpha 3$, and $\beta$. Numbers along right side indicate length of undigested probe. Numbers along left side indicate length of protected products obtained with olfactory or eye RNA. See Materials and Methods for complete description of probes and protected products. Exposure shown was for $70 \mathrm{hr}$ at room temperature.

units in the olfactory tissue. Figure 5 shows coronal sections through the olfactory epithelium. In $A$, the upper part of the nasal cavity is shown. The septum on the right side can be recognized, and several turbinates are covered with olfactory epithelium. The section is stained with an antibody against ACIII. A thin dark line on the surface of the epithelium is stained, representing the cilia of OSNs. In this low-power magnification and wide-field illumination, the cartilage within the turbinates and septum appears dark when photographed in black and white, but it is not stained by the antibodies. In $B$, a section stained with the anti- $\alpha 3$ antibody is shown. Again, the ciliary layer is homogeneously stained. The prominent staining of the cilia is shown at higher magnification in Figure 5C. At anti- $\alpha 3$ dilutions $\leq 1: 100$, weak labeling was ob- served in the somata of OSNs, which appeared mostly of cytoplasmic origin (data not shown). In $D$, a section stained with the antibody mAB7B11 against the $\mathrm{CNC} \alpha 4$ subunit is shown. In the ciliary layer, no staining above background is found. The staining in the submucosal layer reflects unspecific binding of the secondary antibody. We were concerned about the negative result with anti- $\alpha 4$, all the more because Western blot and electrophysiological analyses unequivocally show that $\mathrm{CNC} \alpha 4$ is enriched in cilia and is present in native channels, respectively (Fig. 4 and see below). Therefore, we repeated the stainings with mAB7B11 on tissue specimens that were fixed in different ways (conditions included fixation in $2 \%$ or $4 \%$ paraformaldehyde for 20 or $60 \mathrm{~min}$, or in 1\% 1-ethyl-3-(3-dimethylamino-propyl)carbodiimid, or in methanol at $-20^{\circ} \mathrm{C}$; some specimens were sectioned unfixed, and sections were slightly post-fixed with paraformaldehyde, paraformaldehyde/picric acid mixtures, or methanol). In none of these cases was staining of olfactory cilia observed (F. Müller, data not shown). These negative results do not necessarily indicate the absence of the $\mathrm{CNC} \alpha 4$ subunit from cilia membranes. It is known that some antibodies reliably detect an antigen in Western blots, but fail to stain the fixed antigen in the native tissue because of epitope masking (Kaprielian et al., 1995). Although mAB7B11 did not stain cilia in sections, it unequivocally demonstrated the enrichment of $\mathrm{CNC} \alpha 4$ in cilia preparations by Western blot (Fig. 4). The antiserum FPc $21 \mathrm{~K}$ against the $\beta$ subunit strongly stained cilia of OSNs (Fig. 5E).

To investigate which of the three channel polypeptides coassemble in the ciliary membrane to form a protein complex, we performed immunoprecipitation experiments under nondenaturing conditions. Using any of the three subunit-specific antibodies to precipitate the native channel protein from a solubilized cilia preparation, we found that each of the three subunits could be identified after SDS-PAGE and Western blotting (data not shown). In light of these results it is plausible that all three subunits co-assemble in one protein complex, probably the native CNG channel of the sensory cilia. As we will show below, however, CNG channel subunits can co-assemble into several different channel species. If different channel species do coexist, then it is not possible to distinguish among $\mathrm{CNC} \alpha 3 \beta 1 \mathrm{~b}, \mathrm{CNC} \alpha 4 \beta 1 \mathrm{~b}$, and $\mathrm{CNC} \alpha 3 \alpha 4 \beta 1$ b by immunoprecipitation unless performed in a quantitative and subtractive manner (Tretter et al., 1997; Shamotienko et al., 1997; Jechlinger et al., 1998). Therefore, we have instead investigated the functional properties of the various subunit combinations expressed heterologously, while in parallel characterizing the functional properties of native channels from OSNs.

\section{Functional analysis of subunit composition: macroscopic currents}

As a further analysis of subunit composition, we compared the electrophysiological properties of native channels with channels composed of the cloned subunits. Activity of the native channel was recorded in inside-out patches excised from somatic and dendritic membranes of rat olfactory neurons. Cloned channel subunits were studied in excised inside-out patches of HEK 293 cells transfected with all possible combinations of the cDNAs encoding $\mathrm{CNC} \alpha 3, \mathrm{CNC} \alpha 4$, or $\mathrm{CNC} \beta 1 \mathrm{~b}$. Transfection with the cDNA encoding $\mathrm{CNC} \alpha 3$ alone, as well as the subunit combinations $\mathrm{CNC} \alpha 3 / \mathrm{CNC} \beta 1 \mathrm{~b}, \mathrm{CNC} \alpha 3 / \mathrm{CNC} \alpha 4$, and $\mathrm{CNC} \alpha 3 / \mathrm{CNC} \alpha 4 /$ $\mathrm{CNC} \beta 1 \mathrm{~b}$, produced functional channels (for simplicity referred to in the following as $\alpha 3, \alpha 3 \beta 1 \mathrm{~b}, \alpha 3 \alpha 4$, and $\alpha 3 \alpha 4 \beta 1 \mathrm{~b}$ channels, respectively). Expression of $\mathrm{CNC} \alpha 4$ or $\mathrm{CNC} \beta 1 \mathrm{~b}$ either alone or co-transfected did not produce functional CNG channels. 


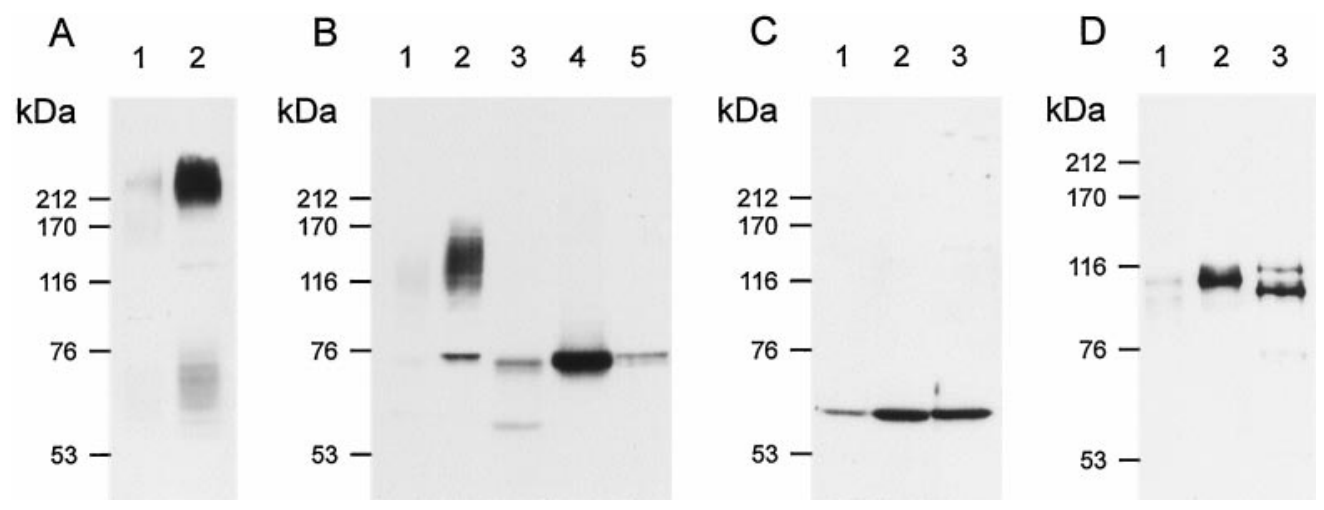

Figure 4. Analysis by Western blot of $\mathrm{CNC} \alpha 3,-\alpha 4$ and $-\beta 1 \mathrm{~b}$ expression in sensory cilia of rat olfactory epithelium. $A$, Western blot of equal amounts of membrane protein prepared from either whole olfactory epithelium (OE) (lane 1) or from isolated olfactory cilia (lane 2) probed with an anti-ACIII-specific antibody produced a much stronger $\sim 230 \mathrm{kDa}$ signal with the cilia preparations. $B$, Western blot probed with polyclonal anti- $\alpha 3$ antibody. The antibody recognized a $\sim 75 \mathrm{kDa}$ band and a "fuzzy" smear between $\sim 110$ and $145 \mathrm{kDa}$ in the preparations from both whole OE (lane 1) and cilia (lane 2). The $\mathrm{CNC} \alpha 3$ subunit expressed in HEK 293 cells displays an apparent molecular mass of $\sim 75 \mathrm{kDa}$ (lane 5, $10 \mu \mathrm{g}$ protein), suggesting that the $75 \mathrm{kDa}$ band recognized in olfactory tissue, in fact, represents the CNC $\alpha 3$ subunit. Treatment of membrane proteins from whole OE (lane 3 ) and cilia (lane 4 ) with $\mathrm{N}$-glycosidase $\mathrm{F}$ abolished the smear entirely and correspondingly increased the intensity of the $75 \mathrm{kDa}$ band. $C$, Western blot of membranes derived from whole OE (lane 1), cilia (lane 2), and HEK 293 cells expressing CNC $\alpha 4$ (lane 3) probed with monoclonal antibody mAB7B11 against the $\mathrm{CNC} \alpha 4$ subunit. $D$, Western blot as in $C$, probed with polyclonal antibody FP21K against CNC $\beta 1$ bubunit. Lane 3 is membrane derived from HEK 293 cells expressing $C N C \beta 1 b$. As seen in $B$ with $C N C \alpha 3$, both the $C N C \alpha 4$ - and - $\beta 1 \mathrm{~b}$ antibodies produced much stronger signals with preparations of cilia membranes, indicating that the molar concentration of the respective polypeptide (relative to the total protein content) is higher in ciliary-enriched than in whole OE membranes.
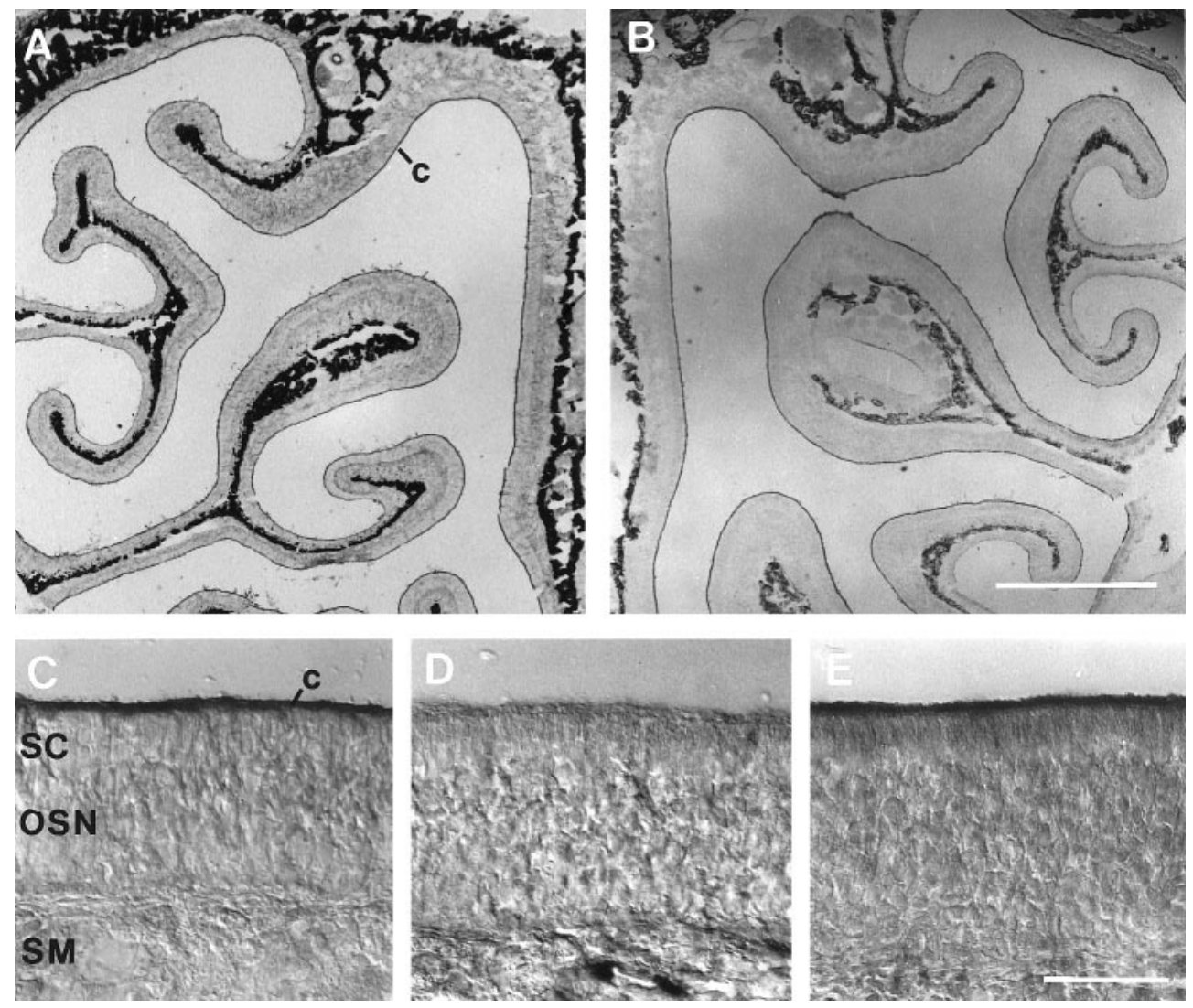

Figure 5. Immunohistochemical staining of olfactory epithelium. $A$, Upper part of the nasal cavity, stained with an antibody against ACIII. Strong staining is found in the thin ciliary layer $(c)$ covering the epithelium on the septum (right border) and turbinates. The cartilage appears dark because of an artifact of the low-power optics but is not stained. $B$, The anti- $\alpha 3$ antibody homogeneously stained the ciliary layer. $C$, Higher magnification of the field shown in $B . D$, Antibody mAB7B11 against the $\mathrm{CNC} \alpha 4$ subunit. No staining above background is found in the cilia. $E$, Purified antiserum FPc21K against the $\beta$ subunit strongly stained the cilia of OSNs. Scale bars: $A$, $B, 1 \mathrm{~mm} ; C-E, 50 \mu \mathrm{m}$.
Ligand sensitivity was determined by recording macroscopic currents at different concentrations of cAMP. Figure $6 A$ shows data for the two extreme cases, $\alpha 3$ and native channels. Figure $6 B$ compares the cAMP dose-response relations derived from these patches. Fitting the Hill equation to the data from each experiment gave values for the concentration of half-maximal activation $\left(K_{1 / 2}\right)$ and the Hill coefficient $(n)$ listed in Table 1 . In agreement with Sautter et al. (1998), the $K_{1 / 2}$ values of native and $\alpha 3 \alpha 4 \beta 1 \mathrm{~b}$ channels are similar ( 4.1 and $4.8 \mu \mathrm{M}$, respectively), whereas the $K_{1 / 2}$ values of all other channels are significantly larger, indicating that all three subunits are necessary for the high cAMP sensitivity of native channels.

$K_{1 / 2}$ values derived from macroscopic currents are only meaningful if the channel population in the patch is homogeneous. If 

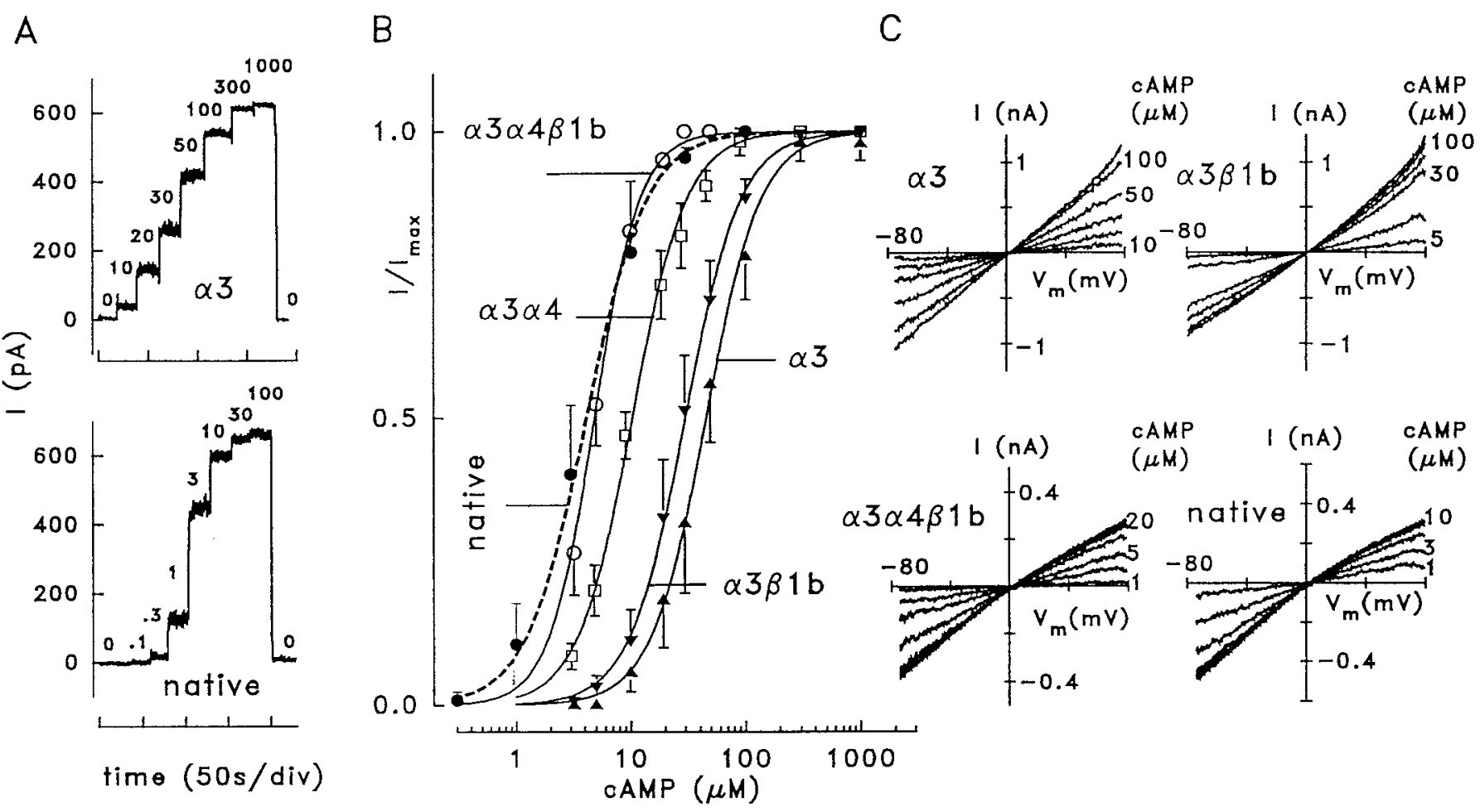

Figure 6. Ligand sensitivity and ion selectivity of native and heterologously expressed olfactory CNG channels. $A$, Macroscopic current recordings from inside-out patches of HEK 293 cells transfected with $\mathrm{CNC} \alpha 3$ and from a patch excised from a dendritic knob of a rat OSN containing native CNG channels. Current was recorded at $+40 \mathrm{mV}$ and the indicated cAMP concentrations. $B$, Dose-response relations for the activation of macroscopic currents by cAMP at $+40 \mathrm{mV}$. Lines were constructed by fitting a Hill-type function to the normalized current (see Materials and Methods). Fitting parameters are given in Table 1. C, Macroscopic currents recorded from inside-out patches with the indicated cAMP concentrations. The main permeable ions were $\mathrm{Na}^{+}$(extracellular) and $\mathrm{K}^{+}$(intracellular). The current shows inward rectification only with $\alpha 3 \alpha 4 \beta 1 \mathrm{~b}$ and native channels, indicating that these channels conduct $\mathrm{Na}^{+}$better than $\mathrm{K}^{+}$.

different kinds of channels are expressed by a cell, the measured $K_{1 / 2}$ value represents the arithmetic mean of the weighted contributions from each channel population. Two observations demonstrate that mixed populations rarely occur with olfactory subunits. First, single-channel recordings show that each combination of olfactory subunits produced a single type of channel in almost all experiments (see below). Second, the cAMP sensitivities derived from macroscopic currents for each channel type (Table 1) and those obtained from open probability analysis of single-channel recordings (Table 2) do not differ significantly, indicating virtually homogeneous channel populations (see below). In conclusion, the co-expression of three subunits produces channels with cAMP sensitivity similar to the native olfactory channel, whereas the $\alpha 3 \beta 1 \mathrm{~b}$ and $\alpha 3 \alpha 4$ combinations result in channels with significantly lower cAMP sensitivity.

The native channel from rat OSNs conducts $\mathrm{Na}^{+}$better than $\mathrm{K}^{+}$. In macroscopic current recordings from the apical membrane of rat OSNs, $\mathrm{K}^{+}$ions produced only half the current amplitude carried by $\mathrm{Na}^{+}$ions $\left(I_{\mathrm{K}} / I_{\mathrm{Na}} \cong 0.5\right)$ (Frings et al., 1992). We used this characteristic feature as an additional indicator of subunit composition of the native olfactory $\mathrm{CNG}$ channel. Figure $6 \mathrm{C}$ compares the $\mathrm{Na}^{+}$and $\mathrm{K}^{+}$ion selectivity of the native channel with that of several subunit combinations. With $140 \mathrm{~mm}$ extracellular $\mathrm{Na}^{+}$and $140 \mathrm{mM} \mathrm{K}{ }^{+}$on the cytosolic side of inside-out patches, the $I-V_{\mathrm{m}}$ relations of $\alpha 3$ and $\alpha 3 \beta 1 \mathrm{~b}$ channels are linear or even slightly outwardly rectifying (Fig. $6 C$, top panels). In contrast, under identical conditions the $I-V_{\mathrm{m}}$ relations of native and $\alpha 3 \alpha 4 \beta 1$ b channels become slightly inwardly rectifying (Fig. $6 C$, bottom panels). The rectification ratios under bi-ionic conditions $\left(I_{+50} / I_{-50}\right)$ of $0.66 \pm 0.05$ (3) for native and $0.73 \pm 0.03$ (2) for $\alpha 3 \alpha 4 \beta 1$ b channels indicate a similar degree of current rectification, distinctly more pronounced than for $\alpha 3[1.05 \pm 0.02(2)]$ and $\alpha 3 \beta 1 \mathrm{~b}[1.13 \pm 0.03(2)]$ channels. Thus, current rectification, as displayed by the native channel with $\mathrm{Na}^{+}$on the outside and $\mathrm{K}^{+}$ on the inside of the membrane, is only observed with the combination of all three subunits.

\section{Functional analysis of subunit composition: single-channel recordings}

A detailed analysis of channel properties requires single-channel recording. Channel conductance, open probability, and kinetics of gating transitions represent characteristic features that distinguish ion channels from each other. Single-channel recordings can be obtained from the membranes of dendrites and somata of OSNs where the channel density is much lower than in the ciliary membrane. This raises the concern that channels investigated in the soma membrane may be different from channels expressed in sensory cilia. However, we will present data indicating that rat OSNs express only a single type of cAMP-gated channel that is expressed both in cilia and somata.

\section{Native channels of rat OSNs}

In all 46 single-channel patches excised from somata, we observed a channel described in Figure 7, suggesting that all cAMP-gated channels in the soma membrane are of the same type. Figure $7 A$ 


\begin{tabular}{lccc}
\hline \multicolumn{3}{l}{ Table 1. Activation of macroscopic currents by cAMP } \\
Channel & $K_{1 / 2}(\mu \mathrm{M})$ & $n$ & Patches \\
\hline$\alpha 3$ & $45.3 \pm 10.6$ & $1.8 \pm 0.2$ & 11 \\
$\alpha 3 \beta 1 \mathrm{~b}$ & $29.9 \pm 6.0$ & $1.8 \pm 0.1$ & 33 \\
$\alpha 3 \alpha 4$ & $10.3 \pm 1.0$ & $1.8 \pm 0.2$ & 6 \\
$\alpha 3 \alpha 4 \beta 1 \mathrm{~b}$ & $4.8 \pm 0.6$ & $2.2 \pm 0.3$ & 8 \\
Native & $4.1 \pm 1.9$ & $1.7 \pm 0.1$ & 4
\end{tabular}

Concentrations for half-maximal activation, $K_{1 / 2}$, of macroscopic currents at +40 $\mathrm{mV}$, together with Hill coefficients, $n$, and numbers of patches.

Table 2. Single-channel parameters of olfactory CNG channels

\begin{tabular}{lcllll} 
& & & \multicolumn{2}{l}{ Rectification ratio } \\
\cline { 5 - 6 } Channel & $K_{1 / 2} / \mu \mathrm{M}$ & $n$ & Symmetrical & Bi-ionic \\
\hline$\alpha 3$ & $40(4)$ & $2.5(4)$ & $1.05(15)$ & $1.03(12)$ \\
$\alpha 3 \beta 1 \mathrm{~b}$ & $28(3)$ & $1.9(3)$ & $1.0(12)$ & $1.03(9)$ \\
$\alpha 3 \alpha 4 \beta 1 \mathrm{~b}$ & $4.0(3)$ & $2.0(3)$ & $1.28(13)$ & $0.57(13)$ \\
Native & $3.4(4)$ & $2.3(4)$ & $1.30(14)$ & $0.55(9)$
\end{tabular}

Concentrations of cAMP, $K_{1 / 2}$, that induced an open probability of 0.5 at $+50 \mathrm{mV}$ (native at $-50 \mathrm{mV}$ ), together with Hill coefficients, $n$, and numbers of experiments in parentheses. Rectification ratios represent $i(+50 \mathrm{mV}) / i(-50 \mathrm{mV})$ with symmetrical $\mathrm{Na}^{+}$or with extracellular $\mathrm{Na}^{+}$and intracellular $\mathrm{K}^{+}$(bi-ionic condition).

shows current recordings obtained from a native channel activated with $1 \mu \mathrm{M}$ cAMP at various membrane voltages in symmetrical $\mathrm{Na}^{+}$solutions. The channel shows a sizeable voltagedependence of $P_{\mathrm{o}}$, displaying prolonged dwell periods in the open state at positive potentials and only brief openings at negative potentials. This voltage dependence is more pronounced at low compared with high cAMP concentrations. The ratio of open probabilities $\left[P_{\mathrm{o}}(-60 \mathrm{mV}) / P_{\mathrm{o}}(+60 \mathrm{mV})\right]$ is $0.17 \pm 0.06(3)$ at 1 $\mu \mathrm{M}$ cAMP and increases to $0.76 \pm 0.13$ (3) at $3 \mu \mathrm{M}$ cAMP. At 3 $\mu \mathrm{M}$ cAMP (Fig. $7 B$ ), the channel is mostly open at positive $V_{\mathrm{m}}$, whereas negative $V_{\mathrm{m}}$ induces frequent transitions between open and closed states. Single-channel currents were derived from amplitude histograms; the two distinct peaks at $0 \mathrm{pA}$ and -1.95 pA represent the closed and open states of the channel, respectively, at $-70 \mathrm{mV}$ (Fig. 7D). Single-channel currents were measured between -80 and $+80 \mathrm{mV}$ (Fig. $7 E$ ); the apparent slope conductance is $27 \mathrm{pS}$ at negative voltages for both symmetrical $\left(\mathrm{Na}^{+}\right)$and bi-ionic $\left(\mathrm{Na}^{+} / \mathrm{K}^{+}\right)$conditions (14 patches). At positive $V_{\mathrm{m}}$, the conductance is $35 \mathrm{pS}$ (five patches) in symmetrical $\mathrm{Na}^{+}$and $14.5 \mathrm{pS}$ (nine patches) in bi-ionic conditions. These values represent an underestimate of the channel conductance because brief opening and closing events are only partially resolved under our recording conditions (see also Torre et al., 1992; Sesti et al., 1994; Bucossi et al., 1997). The particularly high frequency of brief opening and closing events at negative voltages may fully account for the slight outward rectification of singlechannel current at symmetrical solution. Rectification ratios under bi-ionic conditions are consistent between single-channel data from the soma $\left(i_{+50} / i_{-50}=0.55\right)$ and macroscopic recordings from the apical membrane $\left(I_{+50} / I_{-50}=0.66\right)$, indicating that CNG channels with similar $\mathrm{Na}^{+} / \mathrm{K}^{+}$selectivity are expressed in apical and basolateral membranes of OSNs.

Occasionally, the native channel displayed a state of reduced conductance. In this state, channels conduct $\sim 45 \%$ of the current in the main open state (Fig. $7 C$ ). This substate was observed infrequently, could not be correlated with any particular cAMP concentration or membrane voltage, and was typically stable for $10 \mathrm{sec}$ to well over $30 \mathrm{sec}$.

Ligand sensitivity of native channels was analyzed by measuring $P_{\text {o }}$ at various cAMP concentrations (using amplitude histograms derived from recordings of 20-50 sec duration; $-50 \mathrm{mV}$ ) and yielded a $K_{1 / 2}$ of $3.4 \mu \mathrm{M}(n=2.3$; four patches) (Fig. $7 F)$. Thus, the single-channel analysis is in good agreement with the values obtained from macroscopic recordings $(4.1 \pm 1.9 \mu \mathrm{M} ;+40$ $\mathrm{mV}$; Table 1), although they were recorded at different voltages. The small difference between activation constants could be explained by the voltage dependence of $P_{\mathrm{o}}$ illustrated above. For $P_{\mathrm{o}}$ analysis of native channels, it was necessary to record at negative potentials to obtain sufficiently stable patches. This almost perfect match of cAMP sensitivity between channels in the apical membrane and the membrane of somata strongly suggests that the same cAMP-gated channels are expressed in both membranes, probably with the same subunit composition.

\section{$\alpha 3, \alpha 3 \beta 1 b$, and $\alpha 3 \alpha 4$ channels}

We performed a similar single-channel analysis of $\alpha 3$ homomeric channels recorded under bi-ionic conditions. The channel opened for relatively long durations (Fig. 8A); however, it required higher cAMP concentrations than the native channel. Amplitude histograms yielded a linear $i-V_{\mathrm{m}}$ relation (Fig. $\left.8 E, \mathbf{O}\right)$ from which a mean conductance of $34.3 \pm 1.4 \mathrm{pS}$ (nine patches) was calculated. Outward $\left(\mathrm{K}^{+}\right)$conductance was not significantly different from the inward $\left(\mathrm{Na}^{+}\right)$conductance (Table 2). A plot of the open probability versus cAMP concentration, using data obtained from four single-channel recordings at $+50 \mathrm{mV}$ (Fig. $8 F$, ○), was fitted with $K_{1 / 2}=40 \mu \mathrm{M}$ and $n=2.5$ (four patches). $P_{\mathrm{o}}$ was weakly voltage dependent, with $P_{\mathrm{o}}(-60 \mathrm{mV}) / P_{\mathrm{o}}(+60 \mathrm{mV})=0.66 \pm 0.16$ (two patches) at $30 \mu \mathrm{M} \mathrm{cAMP}$.

Co-expression of $\mathrm{CNC} \alpha 3$ with $\mathrm{CNC} \beta 1 \mathrm{~b}$ increased the cAMP affinity and dramatically altered the gating properties of the $\alpha 3$ channel. As illustrated in Figure $8 B$, the $\alpha 3 \beta 1 \mathrm{~b}$ channel displayed a slightly increased cAMP affinity $\left(K_{1 / 2}=28 \mu \mathrm{M}, n=1.9\right)$ (Fig. $8 F, \bigcirc)$ but lost the ability to adopt an open state for prolonged periods. Even at the saturating cAMP concentration of $300 \mu \mathrm{M}$, the channel showed frequent brief closing events, something rarely seen in $\alpha 3$ or native channels at saturating ligand concentrations. Amplitude histograms of the $\alpha 3 \beta 1 \mathrm{~b}$ channel produced two partially overlapping peaks (Fig. $8 D$, solid line) that could be used to calculate the single-channel current and $P_{\mathrm{o}}$. Thus, similar to the heteromeric rod photoreceptor channel (CNC $\alpha 1 / \mathrm{CNC} \beta 1 \mathrm{a})$ (Körschen et al., 1995; Bucossi et al., 1997), the olfactory $\beta$ subunit imparts flickery gating to the heteromeric channel. The $\alpha 3 \beta 1 \mathrm{~b}$ channel, like the $\alpha 3$ channel described above, conducts $\mathrm{K}^{+}$just as well as $\mathrm{Na}^{+}$(Fig. 8E, $\bigcirc ; 12$ patches) (Table 2). Analysis of $P_{\mathrm{o}}$ revealed a very weak voltage dependence with $P_{\mathrm{o}}(-60 \mathrm{mV}) /$ $P_{\mathrm{o}}(+60 \mathrm{mV})=0.87 \pm 0.09(2)$ at $30 \mu \mathrm{M} \mathrm{cAMP}$. Macroscopic and single-channel data are consistent, indicating that macroscopic $\alpha 3 \beta 1 \mathrm{~b}$ currents shown in Figure $6 C$ are determined almost exclusively by the $34 \mathrm{pS}$ channel species. Taken together, we have defined three distinguishing characteristics that set the $\alpha 3$ and $\alpha 3 \beta 1 \mathrm{~b}$ channels apart from the native channel. These include cAMP sensitivity, cation selectivity, and gating kinetics.

Channels consisting of $\mathrm{CNC} \alpha 3$ and $\mathrm{CNC} \alpha 4$ subunits were readily identified by extremely rapid flickering (Fig. $8 \mathrm{C}$ ) that produced a single skewed peak in the amplitude histogram (Fig. $8 D$, dotted line), as reported previously (Bradley et al., 1994; Liman and Buck, 1994; Broillet and Firestein, 1997). These rapid kinetics set the $\alpha 3 \alpha 4$ channels apart from the native channel and 

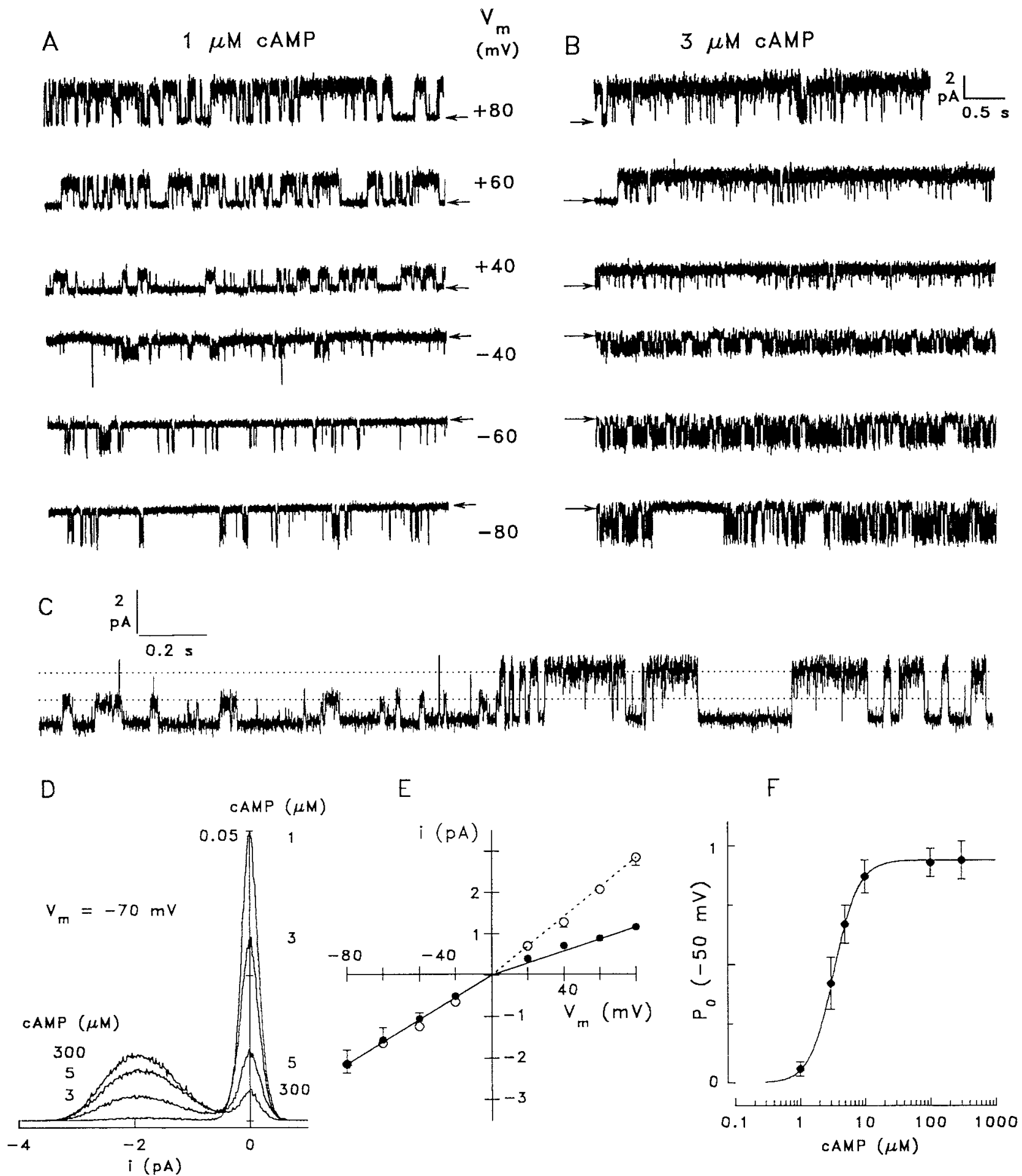

Figure 7. Single-channel analysis of native CNG channels from rat OSNs. $A$, Recording from an inside-out patch with $1 \mu \mathrm{M}$ cAMP at the indicated membrane voltages. Arrows indicate the closed state. The channel shows a significant voltage dependence of open probability. $B$, The same channel as in $A$ at $3 \mu \mathrm{M}$ cAMP. Positive voltages favor the open state, whereas negative voltages induce continuous flickering. Single-channel recordings were obtained in symmetrical $\mathrm{Na}^{+}$solutions, sampled at $3 \mathrm{kHz}$ and filtered at $1 \mathrm{kHz}$. $C$, Transition of the native channel from a state of low conductance (14-16 pS) to the conductance level that is observed most of the time (35 pS); $1 \mu \mathrm{M} \mathrm{cAMP,}+60 \mathrm{mV}$. D, All-point amplitude histograms of four 40 sec recordings from a native channel at $-70 \mathrm{mV}$ and the indicated cAMP concentrations. Although brief, unresolved closing events result in a comparably broad current distribution in the open state (approximately $-1.9 \mathrm{pA}$ ), the two peaks reflecting open and closed states can be clearly distinguished. The ordinate indicates the percentage of total time spent at each current level plotted. $E$, Voltage dependence of the single-channel current recorded in symmetrical $(\bigcirc$, means of 5 channels), and bi-ionic conditions ( $\bullet$, means of 9 channels). The conductance at negative voltages (fitted to the mean values) was $27 \mathrm{pS}$ in both symmetrical and bi-ionic (intracellular $\mathrm{K}^{+}$, extracellular $\mathrm{Na}^{+}$) conditions. At positive voltages the conductance was $35 \mathrm{pS}$ in symmetrical and $14.5 \mathrm{pS}$ in bi-ionic conditions. $F$, Dependence of open probability on cAMP concentration. Single-channel analysis from four patches at $-50 \mathrm{mV}$ yielded $K_{1 / 2}=3.4 \mu \mathrm{M}, n=2.3$. 


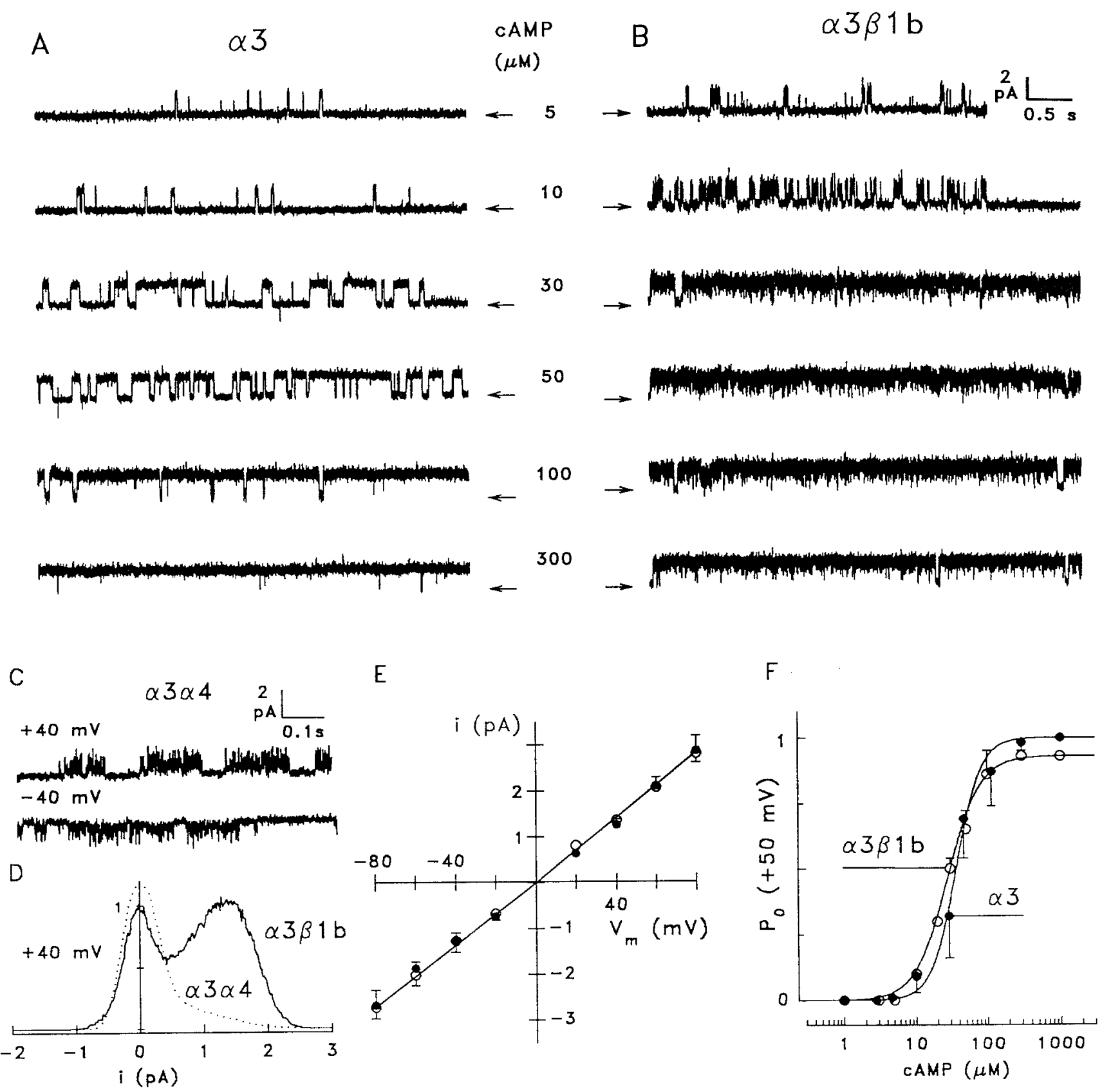

Figure 8. Analysis of channels consisting of $\mathrm{CNC} \alpha 3$ plus the $\mathrm{CNC} \beta 1 \mathrm{~b}$ or $\mathrm{CNC} \alpha 4$ subunit. $A$, Single-channel recording from a homomeric $\alpha 3$ channel at $+50 \mathrm{mV}$ and the indicated concentrations of cAMP. The channel shows a lower ligand sensitivity than native channels and long uninterrupted dwell periods in the open state. $B$, Single-channel recording from a $\alpha 3 \beta 1 \mathrm{~b}$ channel. Coexpression of the CNC $\beta 1 \mathrm{~b}$ subunit slightly increases ligand sensitivity and causes rapid open-closed transitions at both positive and negative membrane voltages. $C$, Recordings from $\alpha 3 \alpha 4$ channels at $10 \mu \mathrm{M}$ cAMP display extremely rapid flickering. $D$, All-point histograms from single-channel recordings from $\alpha 3 \alpha 4$ channels $(10 \mu \mathrm{M} \mathrm{cAMP},+40 \mathrm{mV}$, dotted line $)$ and $\alpha 3 \beta 1 \mathrm{~b}$ channels $(30 \mu \mathrm{M}$ cAMP $+40 \mathrm{mV}$, solid line). The skewed histogram obtained for $\alpha 3 \alpha 4$ channels did not permit determination of single-channel current and open probability. $E$, Voltage dependence of single-channel current yielded an apparent conductance of $33.7 \pm 2.7 \mathrm{pS}$ (12 patches) for $\alpha 3$ ( $)$ and $34.3 \pm 1.4 \mathrm{pS}$ ( 9 patches) for $\alpha 3 \beta 1 \mathrm{~b}$ channels $(\bigcirc)$. F, cAMP dependence of open probability measured at $+50 \mathrm{mV}$. Solid lines were fitted for $\alpha 3$ channels $\left(\bullet, 4\right.$ patches) with $K_{1 / 2}=40 \mu \mathrm{M}, n=2.5$, and for $\alpha 3 \beta 1 \mathrm{~b}$ channels $\left(\bigcirc, 3\right.$ patches) with $K_{1 / 2}=28 \mu \mathrm{M}, n=1.9$.

all other subunit combinations. Opening events were so brief that we could not measure the open-channel current; consequently, single-channel analysis was not feasible with $\alpha 3 \alpha 4$ channels.

\section{Channels containing all three subunits}

When all three subunits were coexpressed, one distinct channel type was observed in almost all of the 54 patches that were analyzed (Fig. 9A), and three single-channel patches permitted analysis of $P_{\mathrm{o}}$. The resulting $K_{1 / 2}$ for activation by cAMP was 4.0 $\mu \mathrm{M}$, with a Hill coefficient of 2.0 (three patches) (Fig. 9B), not significantly different from the native channel. The voltage dependence of single-channel currents is shown in Figure $9 C$. While the $i-V_{\mathrm{m}}$ relation was almost linear in symmetrical $\mathrm{Na}^{+}$solutions, replacement of $\mathrm{Na}^{+}$by $\mathrm{K}^{+}$on the cytosolic side of the patches 
A

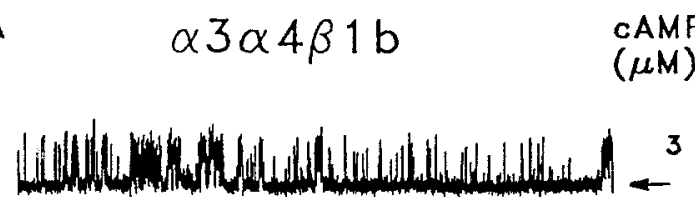

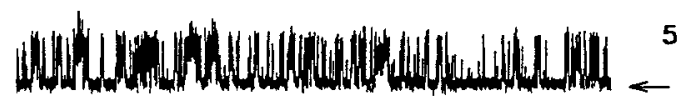


$E$


Figure 9. Single-channel analysis of $\alpha 3 \alpha 4 \beta 1 \mathrm{~b}$ channels. $A$, Single-channel recording from an $\alpha 3 \alpha 4 \beta 1 \mathrm{~b}$ channel at $+50 \mathrm{mV}$ and the indicated concentrations of cAMP. B. Dependence of the open probability on cAMP concentration. Top panel, All-point amplitude histogram of 19-23 sec recordings at $1,3,10$, and $100 \mu \mathrm{M}$ cAMP and $+50 \mathrm{mV}$. Bottom panel, Mean values obtained from four single-channel recordings were fitted with a Hill-type equation using $K_{1 / 2}=4 \mu \mathrm{M}, n=2$, and a maximal $P_{0}$ of 0.9 . C, Voltage dependence of channel current for symmetrical Na ${ }^{+}$solutions (21 pS inward, $27 \mathrm{pS}$ outward) and for bi-ionic solutions ( $21 \mathrm{pS}$ for $\mathrm{Na}^{+}$inward, $12 \mathrm{pS}$ for $\mathrm{K}^{+}$outward currents). $D$, Recording from an $\alpha 3 \alpha 4 \beta 1 \mathrm{~b}$ channel at $+60 \mathrm{mV}$ with $3 \mu \mathrm{M}$ cAMP, showing a $9.5 \mathrm{sec}$ episode during which the channel switched from the main gating state into a substate with reduced conductance and different gating kinetics (arrows). E. Transition of an $\alpha 3 \alpha 4 \beta 1 \mathrm{~b}$ channel from the main conductance state (27 pS) to a subconductance state $\left(15 \mathrm{pS}\right.$, top trace) and back to the main state (bottom trace); $5 \mu \mathrm{M}$ cAMP, $-50 \mathrm{mV}$; symmetrical $\mathrm{Na}^{+}$solutions.

decreased the apparent single-channel conductance for outward currents from $27 \mathrm{pS}\left(\mathrm{Na}^{+}\right)$to $12 \mathrm{pS}\left(\mathrm{K}^{+}\right)$(13 patches). Similar to the native and $\alpha 3 \beta 1 \mathrm{~b}$ channels, these values are underestimates of the channel conductance because of the brief, unresolved opening and closing events. Thus, the apparent conductance of the $\alpha 3 \alpha 4 \beta 1$ b channel is slightly smaller than in native channels, but both channels discriminate between $\mathrm{Na}^{+}$and $\mathrm{K}^{+}$to a similar extent, in contrast to the other heterologously expressed combinations of subunits. A further similarity to native channels is the ability of $\alpha 3 \alpha 4 \beta 1 \mathrm{~b}$ to adopt a subconductance state for extended periods of time. Figure $9 D$ shows a $20 \mathrm{sec}$ record of an $\alpha 3 \alpha 4 \beta 1 \mathrm{~b}$ channel at $3 \mu \mathrm{M}$ cAMP that switches for $9.5 \mathrm{sec}$ (arrows) from the predominant gating mode into a state that displays a smaller conductance, and a more vigorous gating activity. Transitions to and from the subconductance state are shown with better resolution for another $\alpha 3 \alpha 4 \beta 1$ b channel in Figure $9 E$.

Thus, strong similarities are observed between native and $\alpha 3 \alpha 4 \beta 1$ b channels. Closer inspection of single-channel traces, however, do reveal subtle differences in the kinetics of openclosed transitions. Furthermore, the apparent single-channel conductance of the $\alpha 3 \alpha 4 \beta 1 \mathrm{~b}$ channel is slightly smaller then observed in the native channel. However, all other subunit combinations result in channels that show profound functional differences compared with the native olfactory channel. Although we did not find a perfect match between native and $\alpha 3 \alpha 4 \beta 1 \mathrm{~b}$ channels, the similarity of cAMP sensitivity and relative $\mathrm{Na}^{+} / \mathrm{K}^{+}$conductance 
and the ability to adopt a subconductance state, together with the evidence of colocalization and co-assembly of all three subunits in the sensory cilia, strongly suggest that the native channel is composed of the $\mathrm{CNC} \alpha 3, \mathrm{CNC} \alpha 4$, and $\mathrm{CNC} \beta 1 \mathrm{~b}$ subunits.

\section{DISCUSSION}

In this study we report the molecular identification of a $\mathrm{CNG}$ channel $\beta$ subunit, $\mathrm{CNC} \beta 1 \mathrm{~b}$, which represents an alternatively spliced variant of the previously described CNC $\beta 1$ a subunit expressed in rod photoreceptors. In accordance with a previous report (Sautter et al., 1998), we find that 74 amino acid residues in the $\mathrm{CNC} \beta 1 \mathrm{~b}$ subunit replace the large, glutamic acid-rich intracellular domain (GARP) that forms the N-terminal part of CNC $\beta 1$ a (Körschen et al., 1995). Because CNC $\beta 1$ b is the third $\mathrm{CNG}$ channel polypeptide identified in rat olfactory epithelium ( $\mathrm{CNC} \alpha 3, \mathrm{CNC} \alpha 4$, and $\mathrm{CNC} \beta 1 \mathrm{~b}$ ), we examined which of the three subunits contribute to the formation of the native $\mathrm{CNG}$ channel that mediates olfactory transduction.

\section{Subunit composition of the olfactory CNG channel}

We find expression of mRNA coding for all three subunits in OSNs, although the message for $\mathrm{CNC} \alpha 4$ is less abundant than for $\mathrm{CNC} \alpha 3$ and $\mathrm{CNC} \beta 1 \mathrm{~b}$. Using subunit-specific antibodies, we find expression of the three channel polypeptides in the sensory cilia, the site of chemoelectrical signal transduction in OSNs. Furthermore, immunoprecipitation experiments are consistent with the notion that the three polypeptides form a common protein complex in the ciliary membrane. Because the $\mathrm{CNC} \alpha 4$ protein appears to be expressed at a level comparable to $\mathrm{CNC} \alpha 3$ and $\mathrm{CNC} \beta 1 \mathrm{~b}$, the much lower level of $\mathrm{CNC} \alpha 4$ mRNA perhaps indicates differential regulation of translation of these channelencoding messages.

To functionally assess CNG channel subunit composition, we performed a biophysical analysis of the native rat olfactory $\mathrm{CNG}$ channel. Five functional criteria were used to compare native channels with heterologously expressed channels of various subunit composition: (1) the sensitivity for activation by cAMP, (2) the discrimination between $\mathrm{Na}^{+}$and $\mathrm{K}^{+}$, (3) the single-channel conductance, (4) the kinetics of open-closed transitions, and (5) the ability to adopt a subconductance state. Homomeric $\alpha 3$ channels as well as $\alpha 3 \alpha 4$ and $\alpha 3 \beta 1$ b channels display clear differences in all of these criteria relative to the native channel, ruling out that these combinations represent the native subunit composition. In contrast, $\alpha 3 \alpha 4 \beta 1 \mathrm{~b}$ channels resemble the native channel in each of the five criteria tested, strongly supporting the idea that the native olfactory channel consists of the $\mathrm{CNC} \alpha 3, \mathrm{CNC} \alpha 4$, and $\mathrm{CNC} \beta 1 \mathrm{~b}$ subunits. The subtle differences between native and $\alpha 3 \alpha 4 \beta 1$ b channels with respect to the apparent single-channel conductance and the kinetics of open-closed transitions may be the consequence of expression in OSNs versus HEK 293 cells, respectively. In fact, previous studies have shown that the kinetic properties of $\alpha 3 \alpha 4$ channels are influenced by the expression system used. The channels display desensitization when expressed in Xenopus oocytes (Liman and Buck, 1994) but not in HEK 293 cells (Bradley et al., 1994). Even more important, glycosylation of the $\alpha 3$ subunit may affect gating and permeation of the native channel in subtle ways that are absent in the nonglycosylated recombinant channels.

Because of the small size of cilia and the large channel density (Kurahashi and Kaneko, 1991; Kleene et al., 1994; Kleene, 1997), it is not feasible to obtain single-channel data from patches of olfactory cilia or the dendritic knob; instead we resorted to properties of single channels in membranes of the soma and dendrite. This inherent difficulty provokes the question regarding whether somatic and ciliary CNG channels are the same. For example, Torre and coworkers (Torre et al., 1992; Sesti et al., 1994) observed a subpopulation of CNG channels in the inner segment of rod photoreceptors that differs from the channel in the outer segment. However, we consistently observed only a single type of channel in membrane patches of the soma or dendrite of OSNs. Moreover, the cAMP sensitivity and the conductance ratio for $\mathrm{Na}^{+}$and $\mathrm{K}^{+}$measured in channels from the soma of OSNs, and from recombinant $\alpha 3 \alpha 4 \beta 1 \mathrm{~b}$ channels, are very similar to the respective channel properties measured in the membrane patches from the dendritic knob. Because dendritic knob and sensory cilia together form the apical membrane of OSNs, it is reasonable to assume that they contain the same membrane proteins and have the same CNG channels. Although these observations do not entirely rule out the existence of mixed channel populations, they strongly suggest that $\alpha 3 \alpha 4 \beta 1 \mathrm{~b}$ is the predominant channel species in cilia, the dendrite, and the soma.

\section{Implication for olfactory transduction}

The specific contributions of $\mathrm{CNC} \alpha 3, \mathrm{CNC} \alpha 4$, and $\mathrm{CNC} \beta 1 \mathrm{~b}$ to the properties of the native channel have important ramifications for several functional aspects of olfactory transduction. This is because certain key structural features are distinctively different between the three subunits (cAMP-binding site, pore motif, and $\mathrm{N}$ terminus). Some of the implications of channel subunit composition are discussed below.

Olfactory CNG channels are highly permeable to $\mathrm{Ca}^{2+}$ (Frings et al., 1995; Dzeja et al., 1999). A pronounced $\mathrm{Ca}^{2+}$ influx through the CNG channels during odor stimulation causes a rapid increase of the $\mathrm{Ca}^{2+}$ concentration in the lumen of sensory cilia (Leinders-Zufall et al., 1997, 1998). This $\mathrm{Ca}^{2+}$ signal controls both excitation and adaptation of the sensory neuron. Ciliary $\mathrm{Ca}^{2+}$-activated $\mathrm{Cl}^{-}$channels conduct a depolarizing $\mathrm{Cl}^{-}$current that probably represents a large fraction of the receptor current (Kleene and Gesteland, 1991; Kurahashi and Yau, 1993; Lowe and Gold, 1993; Hallani et al., 1998; Reuter et al., 1998). The $\mathrm{Ca}^{2+}$ signal also terminates the sensory response through a CaM-mediated decrease of CNG channel activity (Chen and Yau, 1994; Kurahashi and Menini, 1997). Because of the prominent role of $\mathrm{Ca}^{2+}$ in olfactory signal transduction, it is important to understand how the $\mathrm{CNC} \alpha 3,-\alpha 4$, and $-\beta 1 \mathrm{~b}$ subunits contribute to the $\mathrm{Ca}^{2+}$ conductance of the native channel. All known $\alpha$ subunits contain a negatively charged residue in the pore motif $\left(\mathrm{Glu}^{342}\right.$ in $\mathrm{CNC} \alpha 3, \mathrm{Asp}^{234}$ in $\mathrm{CNC} \alpha 4$ ). These residues form an intrapore $\mathrm{Ca}^{2+}$-binding site of high affinity (Frings et al., 1995; Seifert et al., 1999), which is crucial for ion selectivity, gating, and blockage by extracellular $\mathrm{Ca}^{2+}$ ions (Root and MacKinnon, 1993; Eismann et al., 1994; Sesti et al., 1995; Bucossi et al., 1996). The olfactory $\mathrm{CNC} \beta 1 \mathrm{~b}$ subunit carries an uncharged glycine residue $\left(\right.$ Gly $\left.^{463}\right)$ at the homologous position of its pore motif. As discussed in Dzeja et al. (1999) and Seifert et al. (1999), pores containing $\beta$ subunit(s) are less "sticky" than pores consisting only of $\alpha$ subunits. Consequently, $\mathrm{Ca}^{2+}$ is expected to pass more readily through heterooligomeric $(\alpha+\beta)$ compared with homomeric (only $\alpha$ ) channels. Therefore, the heterooligomeric channels containing this $\beta$ subunit should have different $\mathrm{Ca}^{2+}$ permeability from that of channels consisting of $\alpha$ subunits alone.

Adaptation in OSNs is a $\mathrm{Ca}^{2+}$-dependent process, driven by the binding of $\mathrm{Ca}^{2+} / \mathrm{CaM}$ to the channel. A CaM-binding site in the N-terminal region of the $\mathrm{CNC} \alpha 3$ subunit (Liu et al., 1994) 
binds $\mathrm{CaM}$ with high affinity in a $\mathrm{Ca}^{2+}$-dependent manner, thereby reducing the apparent ligand sensitivity. The $\mathrm{N}$ terminus of $\mathrm{CNC} \alpha 4$ is shorter than that of $\mathrm{CNC} \alpha 3$ by 108 amino acid residues, and it lacks the CaM-binding site. Recently, a CaMbinding site was identified in the $\mathrm{N}$-terminal region of the retinal CNC $\beta 1$ a subunit and was shown to bestow CaM sensitivity to heterologously expressed $\alpha 1 \beta 1$ a channels (Grunwald et al., 1998; Weitz et al., 1998). This site is also present in the olfactory $\mathrm{CNC} \beta 1 \mathrm{~b}$ subunit. Recent studies have shown that native olfactory $\mathrm{CNG}$ channels show characteristic differences in response to CaM compared with $\alpha 3$ homomeric channels. The $K_{1 / 2}$ for cAMP of the native channel can increase by 20 - to 60 -fold (compared with only tenfold in $\mathrm{CNC} \alpha 3$ homomers), and in contrast to $\mathrm{CNC} \alpha 3$ homomers, the open probability at saturating cAMP concentrations is not suppressed (Chen and Yau, 1994; Balasubramanian et al., 1996). These differences may indicate that the $\mathrm{CNC} \alpha 4$ and $\mathrm{CNC} \beta 1 \mathrm{~b}$ subunits participate in the $\mathrm{CaM}$ effect on the native channel. Therefore, investigation of $\alpha 3 \alpha 4 \beta 1 \mathrm{~b}$ channels should further our understanding of the negative feedback regulation that leads to adaptation in OSNs.

Finally, we have recently shown that the ligand sensitivity of $\alpha 3$ channels can be increased tenfold by protein phosphorylation (Müller et al., 1998). When a single serine residue in the $\mathrm{N}$ terminus $\left(\mathrm{Ser}^{95}\right)$ is phosphorylated by protein kinase $\mathrm{C}$ (PKC), the channel is activated at lower cAMP concentrations. This serine residue is conserved in all $\mathrm{CNC} \alpha 3$ orthologs but is missing in $\mathrm{CNC} \alpha 4$. The $\mathrm{N}$ terminus of $\mathrm{CNC} \beta 1 \mathrm{~b}$ contains several consensus sequences for $\mathrm{PKC}$, but any functional roles of these sites await assessment. Future coexpression studies with the $\mathrm{CNC} \alpha 3$, $-\alpha 4$, and $-\beta 1 \mathrm{~b}$ subunits should yield important insights into the regulation of the native olfactory $\mathrm{CNG}$ channel. This will promote our understanding not only of olfactory signal transduction, but also of other sensory and nonsensory signal transduction systems that use these CNG channel subunits.

\section{REFERENCES}

Anholt RRH, Aebi U, Snyder SH (1986) A partially purified preparation of isolated chemosensory cilia from the olfactory epithelium of the bullfrog, Rana catesbeiana. J Neurosci 6:1962-1965.

Ardell MD, Aragon I, Oliveira L, Porche GE, Burke E, Pittler SJ (1996) The $\beta$ subunit of human rod photoreceptor cGMP-gated cation channel is generated from a complex transcription unit. FEBS Lett 389:213-218

Bakalyar HA, Reed RR (1990) Identification of a specialized adenylyl cyclase that may mediate odorant detection. Science 250:1403-1406.

Balasubramanian S, Lynch JW, Barry PH (1996) Calcium-dependent modulation of the agonist affinity of the mammalian olfactory cyclic nucleotide-gated channel by calmodulin and a novel endogenous factor. J Membr Biol 152:13-23.

Baumann A, Frings S, Godde M, Seifert R, Kaupp UB (1994) Primary structure and functional expression of a Drosophila cyclic nucleotidegated channel present in eyes and antennae. EMBO J 13:5040-5050.

Bönigk W, Altenhofen W, Müller F, Dose A, Illing M, Molday RS, Kaupp UB (1993) Rod and cone photoreceptor cells express distinct genes for cGMP-gated channels. Neuron 10:865-877.

Bradley J, Li J, Davidson N, Lester HA, Zinn K (1994) Heteromeric olfactory cyclic nucleotide-gated channels: a new subunit that confers increased sensitivity to cAMP. Proc Natl Acad Sci USA 91:8890-8894.

Bradley J 1996. Molecular analysis of olfactory signal transduction. PhD thesis, Caltech.

Bradley J, Zhang Y, Bakin R, Lester HA, Ronnett GV, Zinn K (1997) Functional expression of the heteromeric "olfactory" cyclic nucleotidegated channel in the hippocampus: a potential effector of synaptic plasticity in brain neurons. J Neurosci 17:1993-2005.

Broillet M-C, Firestein S (1997) $\beta$ subunits of the olfactory cyclic nucleotide-gated channel form a nitric oxide activated $\mathrm{Ca}^{2+}$ channel. Neuron 18:951-958.
Bucossi G, Eismann E, Sesti F, Nizzari M, Seri M, Kaupp UB, Torre V (1996) Time-dependent current decline in cyclic GMP-gated bovine channels caused by point mutations in the pore region expressed in Xenopus oocytes. J Physiol (Lond) 493:409-418.

Bucossi G, Nizzari M, Torre V (1997) Single-channel properties of ionic channels gated by cyclic nucleotides. Biophys J 72:1165-1181.

Chen T-Y, Yau K-W (1994) Direct modulation by $\mathrm{Ca}^{2+}$-calmodulin of cyclic nucleotide-activated channel of rat olfactory receptor neurons. Nature 368:545-548.

Chen Z, Pace U, Heldman J, Shapira A, Lancet D (1986) Isolated frog olfactory cilia: a preparation of dendritic membranes from chemosensory neurons. J Neurosci 6:2146-2154.

Chen T-Y, Peng Y-W, Dhallan RS, Ahamed B, Reed RR, Yau K-W (1993) A new subunit of the cyclic nucleotide-gated cation channel in retinal rods. Nature 362:764-767.

Chen T-Y, Illing M, Molday LL, Hsu Y-T, Yau K-W, Molday RS (1994) Subunit 2 (or $\beta$ ) of retinal rod cGMP-gated cation channel is a component of the $240-\mathrm{kDa}$ channel-associated protein and mediates $\mathrm{Ca}^{2+}$. calmodulin modulation. Proc Natl Acad Sci USA 91:11757-11761.

Cook NJ, Hanke W, Kaupp UB (1987) Identification, purification, and functional reconstitution of the cyclic GMP-dependent channel from rod photoreceptors. Proc Natl Acad Sci USA 84:585-589.

Dhallan RS, Yau K-W, Schrader KA, Reed RR (1990) Primary structure and functional expression of a cyclic nucleotide-activated channel from olfactory neurons. Nature 347:184-187.

Dzeja C, Hagen V, Kaupp UB, Frings S (1999) $\mathrm{Ca}^{2+}$ permeation in cyclic nucleotide-gated channels. EMBO J 18:131-144.

Eismann E, Müller F, Heinemann SH, Kaupp UB (1994) A single negative charge within the pore region of a cGMP-gated channel controls rectification, $\mathrm{Ca}^{2+}$ blockage and ionic selectivity. Proc Natl Acad Sci USA 91:1109-1113.

Finn JT, Grunwald ME, Yau K-W (1996) Cyclic nucleotide-gated ion channels: an extended family with diverse functions. Annu Rev Physiol 58:395-426.

Frings S, Lynch JW, Lindemann B (1992) Properties of cyclic nucleotide-gated channels mediating olfactory transduction: activation, selectivity, and blockage. J Gen Physiol 100:45-67.

Frings S, Seifert R, Godde M, Kaupp UB (1995) Profoundly different calcium permeation and blockage determine the specific function of distinct cyclic nucleotide-gated channels. Neuron 15:169-179.

Frohman MA, Dush MK, Martin GR (1988) Rapid production of fulllength cDNAs from rare transcripts: amplification using a single genespecific oligonucleotide primer. Proc Natl Acad Sci USA 85:8998-9002.

Gordon SE, Oakley JC, Varnum MD, Zagotta WN (1996) Altered ligand specificity by protonation in the ligand binding domain of cyclic nucleotide-gated channels. Biochemistry 35:3994-4001.

Goulding EH, Ngai J, Kramer RH, Colicos S, Axel R, Siegelbaum SA, Chess A (1992) Molecular cloning and single-channel properties of the cyclic nucleotide-gated channel from catfish olfactory neurons. Neuron 8:45-58.

Grunwald ME, Yu W-P, Yu H-H, Yau K-W (1998) Identification of a domain on the $\beta$-subunit of the rod cGMP-gated cation channel that mediates inhibition by calcium-calmodulin. J Biol Chem 273:9148-9157.

Hallani M, Lynch JW, Barry PH (1998) Characterization of calciumactivated chloride channels in patches excised from the dendritic knob of mammalian olfactory receptor neurons. J Membr Biol 161:163-171.

Hamill OP, Marty A, Neher E, Sakmann B, Sigworth FJ (1981) Improved patch-clamp techniques for high-resolution current recording from cells and cell-free membrane patches. Pflügers Arch 391:85-100.

Henn DK, Baumann A, Kaupp UB (1995) Probing the transmembrane topology of cyclic nucleotide-gated ion channels with a gene fusion approach. Proc Natl Acad Sci USA 92:7425-7429.

Hsu Y-T, Molday RS (1993) Modulation of the cGMP-gated channel of rod photoreceptor cells by calmodulin. Nature 361:76-79.

Jan LY, Jan YN (1990) A superfamily of ion channels. Nature 345:672. Jechlinger M, Pelz R, Tretter V, Klausberger T, Sieghart W (1998) Subunit composition and quantitative importance of hetero-oligomeric receptors: $\mathrm{GABA}_{\mathrm{A}}$ receptors containing $\alpha_{6}$ subunits. J Neurosci 18:2449-2457.

Kaprielian Z, Cho KO, Hadjargyrou M, Patterson PH (1995) CD9, a major platelet cell surface glycoprotein, is a ROCA antigen and is expressed in the nervous system. J Neurosci 15:565-573.

Kaupp UB (1995) Family of cyclic nucleotide gated ion channels. Curr Opin Neurobiol 5:434-442. 
Kaupp UB, Niidome T, Tanabe T, Terada S, Bönigk W, Stühmer W, Cook NJ, Kangawa K, Matsuo H, Hirose T, Miyata T, Numa S (1989) Primary structure and functional expression from complementary DNA of the rod photoreceptor cyclic GMP-gated channel. Nature 342:762-766.

Kleene SJ (1997) High-gain, low-noise amplification in olfactory transduction. Biophys J 73:1110-1117.

Kleene SJ, Gesteland RC (1991) Calcium-activated chloride conductance in frog olfactory cilia. J Neurosci 11:3624-3629.

Kleene SJ, Gesteland RC, Bryant SH (1994) An electrophysiological survey of frog olfactory cilia. J Exp Biol 195:307-328.

Körschen HG, Illing M, Seifert R, Sesti F, Williams A, Gotzes S, Colville C, Müller F, Dosé A, Godde M, Molday L, Kaupp UB, Molday RS (1995) A $240 \mathrm{kDa}$ protein represents the complete $\beta$ subunit of the cyclic nucleotide-gated channel from rod photoreceptor. Neuron 15:627-636.

Kurahashi T, Kaneko A (1991) High density cAMP-gated channels at the ciliary membrane in the olfactory receptor cell. NeuroReport 2:5-8.

Kurahashi T, Menini A (1997) Mechanism of odorant adaptation in the olfactory receptor cell. Nature 385:725-729.

Kurahashi T, Yau K-W (1993) Co-existence of cationic and chloride components in odorant-induced current of vertebrate olfactory receptor cells. Nature 363:71-74.

Leinders-Zufall T, Rand MN, Shepherd GM, Greer CA, Zufall F (1997) Calcium entry through cyclic nucleotide-gated channels in individual cilia of olfactory receptor cells: spatiotemporal dynamics. J Neurosci 17:4136-4148.

Leinders-Zufall T, Greer CA, Shepherd GM, Zufall F (1998) Imaging odor-induced calcium transients in single olfactory cilia: specificity of activation and role in transduction. J Neurosci 18:5630-5639.

Liman ER, Buck LB (1994) A second subunit of the olfactory cyclic nucleotide-gated channel confers high sensitivity to cAMP. Neuron 13:611-621.

Liu DT, Tibbs GR, Siegelbaum SA (1996) Subunit stoichiometry of cyclic nucleotide-gated channels and effects of subunit order on channel function. Neuron 16:983-990.

Liu M, Chen T-Y, Ahamed B, Li J, Yau K-W (1994) Calciumcalmodulin modulation of the olfactory cyclic nucleotide-gated cation channel. Science 266:1348-1354.

Lowe G, Gold GH (1993) Nonlinear amplification by calcium-dependent chloride channels in olfactory receptor cells. Nature 366:283-286.

Ludwig J, Margalit T, Eismann E, Lancet D, Kaupp UB (1990) Primary structure of cAMP-gated channel from bovine olfactory epithelium. FEBS Lett 270:24-29.

Menco BPM, Bruch RC, Dau B, Danho W (1992) Ultrastructural localization of olfactory transduction components: the $\mathrm{G}$ protein subunit $\mathrm{G}_{\mathrm{olf} \alpha}$ and type III adenylyl cyclase. Neuron 8:441-453.

Molday LL, Cook NJ, Kaupp UB, Molday RS (1990) The cGMP-gated cation channel of bovine rod photoreceptor cells is associated with a 240-kDa protein exhibiting immunochemical cross-reactivity with spectrin. J Biol Chem 265:18690-18695.

Müller F, Bönigk W, Sesti F, Frings S (1998) Phosphorylation of mammalian olfactory cyclic nucleotide-gated channels increases ligand sensitivity. J Neurosci 18:164-173.
Pace U, Hanski E, Salomon Y, Lancet D (1985) Odorant-sensitive adenylate cyclase may mediate olfactory reception. Nature 316:255-258.

Pfeuffer E, Mollner S, Lancet D, Pfeuffer T (1989) Olfactory adenylyl cyclase. J Biol Chem 264:18803-18807.

Reuter D, Zierold K, Schröder W, Frings S (1998) A depolarizing chloride current contributes to chemo-electrical transduction in olfactory sensory neurons in situ. J Neurosci 18:6623-6630.

Root MJ, MacKinnon R (1993) Identification of an external divalent cation-binding site in the pore of a cGMP-activated channel. Neuron 11:459-466.

Sautter A, Zong X, Hofmann F, Biel M (1998) An isoform of the rod photoreceptor cyclic nucleotide-gated channel $\beta$ subunit expressed in olfactory neurons. Proc Natl Acad Sci USA 95:4696-4701.

Schaeren-Wiemers N, Gerfin-Moser A (1993) A single protocol to detect transcripts of various types and expression levels in neural tissues and cultured cells: in situ hybridization using digoxigenin-labeled cRNA probes. Histochemistry 100:431-440.

Schaffner W, Weissmann C (1973) A rapid, sensitive, and specific method for the determination of protein in dilute solution. Anal Biochem 56:502-514.

Seifert R, Eismann E, Ludwig J, Baumann A, Kaupp UB (1999) Molecular determinants of a $\mathrm{Ca}^{2+}$-binding site in the pore of cyclic nucleotide-gated channels: S5/S6 segments control affinity of intrapore glutamates. EMBO J 18:119-130.

Sesti F, Straforini M, Lamb TD, Torre V (1994) Gating, selectivity and blockage of single channels activated by cyclic GMP in retinal rods of the tiger salamander. J Physiol (Lond) 474:203-222.

Sesti F, Eismann E, Kaupp UB, Nizzari M, Torre V (1995) The multiion nature of cGMP-gated channel from vertebrate rods. J Physiol (Lond) 487:17-36.

Shamotienko OG, Parcej DN, Dolly JO (1997) Subunit combinations defined for $\mathrm{K}^{+}$channel Kv1 subtypes in synaptic membranes from bovine brain. Biochemistry 36:8195-8201.

Torre V, Straforini M, Sesti F, Lamb TD (1992) Different channelgating properties of two classes of cyclic GMP-activated channel in vertebrate photoreceptors. Proc R Soc Lond B Biol Sci 250:209-215.

Tretter V, Ehya N, Fuchs K, Sieghart W (1997) Stoichiometry and assembly of a recombinant $\mathrm{GABA}_{\mathrm{A}}$ receptor subtype. J Neurosci 17:2728-2737.

Vasser R, Ngai J, Axel R (1993) Spatial segregation of odorant-receptor expression in the mammalian olfactory epithelium. Cell 74:309-318.

Weitz D, Zoche M, Müller F, Beyermann M, Körschen HG, Kaupp UB, Koch K-W (1998) Calmodulin controls the rod photoreceptor CNG channel through an unconventional binding site in the N-terminus of the $\beta$-subunit. EMBO J 17:2273-2284.

Weyand I, Godde M, Frings S, Weiner J, Müller F, Altenhofen W, Hatt H, Kaupp UB (1994) Cloning and functional expression of a cyclicnucleotide-gated channel from mammalian sperm. Nature 368:859-863.

Wiesner BWJ, Middendorf R, Hagen V, Kaupp UB, Weyand I (1998) Cyclic nucleotide-gated channels on the flagellum control $\mathrm{Ca}^{2+}$ entry into sperm. J Cell Biol 142:473-484.

Zagotta WN, Siegelbaum SA (1996) Structure and function of cyclic nucleotide-gated channels. Annu Rev Neurosci 19:235-263. 